\title{
Neoadjuvant treatment of pancreatic adenocarcinoma: a systematic review and meta-analysis of 5520 patients
}

\author{
Mashaal Dhir ${ }^{1}$, Gautam K. Malhotra², Davendra P.S. Sohal ${ }^{3}$, Nicholas A. Hein ${ }^{4}$, Lynette M. Smith ${ }^{4}$, Eileen M. O'Reilly ${ }^{5}$,
} Nathan Bahary ${ }^{6}$ and Chandrakanth Are ${ }^{7,8^{*}}$

\begin{abstract}
Background: Recent years have seen standardization of the anatomic definitions of pancreatic adenocarcinoma, and increasing utilization of neoadjuvant therapy (NAT). The aim of the current review was to summarize the evidence for NAT in pancreatic adenocarcinoma since 2009, when consensus criteria for resectable (R), borderline resectable (BR), and locally advanced (LA) disease were endorsed.

Methods: PubMed search was undertaken along with extensive backward search of the references of published articles to identify studies utilizing NAT for pancreatic adenocarcinoma. Abstracts from ASCO-GI 2014 and 2015 were also searched.

Results: A total of 96 studies including 5520 patients were included in the final quantitative synthesis. Pooled estimates revealed $36 \%$ grade $\geq 3$ toxicities, $5 \%$ biliary complications, $21 \%$ hospitalization rate and low mortality (0\%, range $0-16 \%)$ during NAT. The majority of patients $(59 \%)$ had stable disease. On an intention-to-treat basis, R0-resection rates varied from $63 \%$ among R patients to $23 \%$ among LA patients. R0 rates were $>80 \%$ among all patients who were resected after NAT. Among R and BR patients who underwent resection after NAT, median OS was 30 and 27.4 months, respectively.

Conclusions: The current study summarizes the recent literature for NAT in pancreatic adenocarcinoma and demonstrates improving outcomes after NAT compared to those historically associated with a surgery-first approach for pancreatic adenocarcinoma.
\end{abstract}

Keywords: Pancreatic cancer, Pancreatic adenocarcinoma, Neoadjuvant therapy, Outcomes, Survival

\section{Background}

Pancreatic cancer is one of the leading causes of cancerrelated mortality with an estimated 53,670 new cases and an estimated 43,090 deaths in 2017 [1]. The overall survival for all patients with pancreatic cancer remains dismal-approximately $7 \%$ at 5 years [2-4]. Most of the patients present with metastatic disease. Even for those without metastatic disease, surgical treatment can be complex given the local extent of the tumor, with only $10-20 \%$ being candidates for upfront surgery, and these

\footnotetext{
* Correspondence: care@unmc.edu

${ }^{7}$ Department of Surgery, Division of Surgical Oncology, University of Nebraska Medical Center, Omaha, NE 98198, USA

${ }^{8}$ Department of Surgery/Genetics, Cell Biology and Anatomy, University of Nebraska Medical Center, Omaha, NE 68198, USA

Full list of author information is available at the end of the article
}

operable patients may experience 5 year survival of 10 $30 \%$ [3]. Recent years have seen several advances in the management of pancreatic adenocarcinoma. In 2009, an expert consensus statement defined the criteria (based on vascular involvement assessed by preoperative imaging) based on which non-metastatic pancreatic adenocarcinoma is broadly categorized into three categories: resectable, borderline resectable and locally advanced disease [5-7]. Although subtle differences remain between the different consensus criteria $(\mathrm{NCCN}$, Intergroup, AHPBA/SSO, etc.) based on the extent of vascular involvement, these definitions have made the anatomic classification of pancreatic adenocarcinoma more uniform and have made cross study comparisons more reliable. 
Since 1997, gemcitabine has been the reference drug for advanced pancreatic cancer after a randomized trial reported a marginal improvement in overall survival and improved quality of life over 5-FU alone (5.6 vs 4.4 months, $p=0.0025$ ) [8]. Systemic therapy for advanced pancreatic adenocarcinoma (including metastatic disease) has improved with the availability of more effective chemotherapeutic regimens such as FOLFIRINOX (median OS 11.1 months, RR 31.6\%) and gemcitabine with nab-paclitaxel (median OS 8.5 months, RR 23\%). [9, 10] Advances in the chemotherapeutic treatment of metastatic pancreatic adenocarcinoma have been extrapolated to other potentially resectable categories of pancreatic adenocarcinoma [9-15]. More aggressive multimodality treatments have been employed for the management of resectable and borderline resectable tumors in addition to locally advanced tumors [11-13]. Imaging modalities (pancreas protocol CT scan) and radiation delivery techniques such as IMRT and SBRT have evolved which have further advanced the care of these patients.

Neoadjuvant treatment (NAT) strategies are increasingly being employed for borderline resectable and resectable tumors [11-13]. These strategies lead to early initiation of systemic therapy in these patients in contrast to a surgery first approach where up to half of the patients may not receive adjuvant therapy due to postoperative complications or decline in functional status [16-18]. Theoretically, the neoadjuvant approach downstages nodal disease, increases the rate of margin negative resection, and also helps to identify patients at risk of early disease progression [19, 20].

Although previous authors have elegantly reviewed the literature on the subject, recent years have seen several advancements as mentioned above [21-23]. The aim of

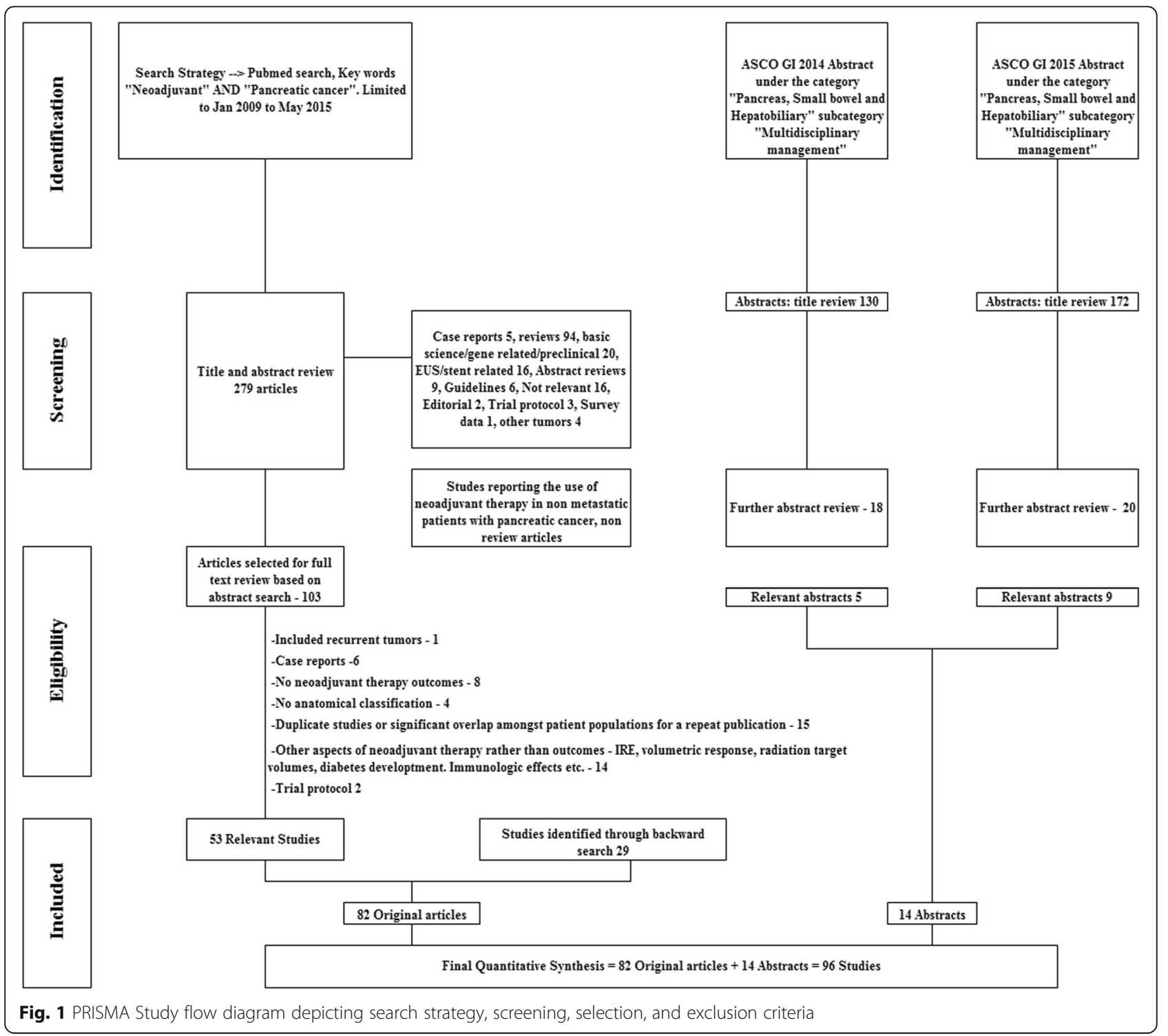


the current study was to perform a systematic review of the literature since 2009 (the year in which the expert consensus criteria were endorsed by several surgical societies) and summarize the current landscape for the role and outcomes of neoadjuvant therapy in the treatment of all non-metastatic anatomic subcategories of pancreatic cancer, i.e., resectable, borderline resectable and locally advanced unresectable disease.

\section{Methods}

\section{Search strategy}

Articles in PubMed database from January, 2009 to May 2015 were searched using the key words "Neoadjuvant" [All Fields] AND "Pancreatic cancer" [All Fields]. Such a search strategy was chosen to capture any English language article reporting on the neoadjuvant treatment of pancreatic cancer. PubMed database was used as it remains one of the most widely used medical literature resources, and only indexes peer-reviewed biomedical literature [24].

\section{Inclusion and exclusion criteria}

Title and abstract review was performed for 279 articles to identify relevant articles. Studies reporting the use of neoadjuvant therapies in non-metastatic patients with pancreatic adenocarcinoma were selected for full text review. Case reports, letters, and review articles were excluded. The search strategy is depicted in detail in Fig. 1. Prospective or retrospective studies of patients with pancreatic adenocarcinoma treated with neoadjuvant therapies (including chemotherapy, chemoradiotherapy or radiotherapy) were evaluated. All phase 1-2 clinical trials, cohort studies and case series were included. Only studies of patients with pancreatic adenocarcinoma were included. Studies reporting combined outcomes of periampullary tumors were excluded. All identified case reports and studies with identical patient cohorts over a similar time period were excluded. A backward search was also performed using bibliographies of relevant articles and review articles to ensure a comprehensive search.

Additionally, abstracts from American Society of Clinical Oncology, Gastrointestinal Cancer Symposium (ASCO GI) under the categories "Cancers of the Pancreas, Small Bowel, and Hepatobiliary Tract" AND "Multidisciplinary Treatment" were reviewed. Title review was performed for 302 abstracts of which 38 were further selected for abstract and review of online posters. Fifteen relevant abstracts were included in the qualitative and quantitative synthesis. Search for conference abstracts was limited as there may be differences in the data presented in the initial abstract and final publication [25].

Figure 1 depicts the study flow diagram. Preferred Reporting Items for Systematic Reviews and Meta- analysis (PRISMA) guidelines were followed with regards to reporting of results [26]. A checklist has been included in the supplementary files.

\section{Data extraction and definitions}

Data were extracted from the selected articles by the first and second author (M.D. and G.M.). Inconsistencies were resolved by discussion and consulting the corresponding author when needed. Data extracted included first author, article type, journal, study methodology, type of neoadjuvant therapy, regimen details, type of tumors (resectable, borderline resectable, locally advanced or combinations thereof), number of patients, radiologic response (complete response, partial response, stable disease, progression), overall and grade 3 toxicity of neoadjuvant therapy, grade 3 toxicities of specific types (i.e., anemia, leukopenia, lymphopenia, neutropenia, febrile neutropenia, thrombocytopenia, fatigue, nausea/vomiting, diarrhea, anorexia, weight loss, biliary obstruction/ cholangitis, gastritis/duodenitis/GI bleed), readmission rates, mortality associated with neoadjuvant therapy, pathologic response, overall survival, and progressionfree survival.

For the calculation of toxicities, radiologic response, and resection rates only studies reporting the outcomes of all patients who underwent neoadjuvant therapy followed by restaging were included. Studies reporting the outcomes of only patients resected after neoadjuvant therapy were included in the calculation of postoperative morbidity and mortality. For studies reporting on combination of various anatomic categories, e.g., borderline resectable and locally advanced, data were recorded separately wherever feasible. When different anatomic subcategories could not be used separately for data extrapolation due to reporting of combined outcomes such studies were listed under BR + LA (borderline resectable and locally advanced patients) and $\mathrm{R}+\mathrm{BR}+\mathrm{LA}$ (resectable, borderline resectable, and locally advanced). Only BR + LA category results were reported given the limited number of patients in the other combined categories. Similarly, for double-armed studies or retrospective studies reporting on two different treatment types, data were recorded separately wherever feasible. The data extraction process was performed twice to ensure the accuracy of the data. Data were also recorded on vascular resections especially for BR and LA categories, dose of radiation therapy, age and gender of the study population, number of cycles of chemotherapy, adjuvant therapy, and follow up to assess the quality of the studies. However, given lack of consensus to assess the quality of non-randomized clinical trials, all studies were included based on completeness of data and inclusion/exclusion criteria. 
Table 1 Summary of studies included in the quantitative analysis

\begin{tabular}{ccc}
\hline & $N$ & $\%$ \\
\hline Total number of studies included & 96 & \\
Original articles & 82 & 85.4 \\
Abstracts & 14 & 14.6 \\
Year of publication & & \\
2009 & 6 & 6.3 \\
2010 & 7 & 7.3 \\
2011 & 8 & 8.3 \\
2012 & 12 & 12.5 \\
2013 & 17 & 17.7 \\
2014 & 29 & 30.2 \\
2015 & 17 & 17.7
\end{tabular}

Global distribution of location of institutions of selected studies

$\begin{array}{lll}\text { North America } & 54 & 56.3 \\ \text { Europe } & 21 & 21.9 \\ \text { Asia } & 18 & 18.7 \\ \text { Australia/Africa/South America (1 each) } & 3 & 3.1\end{array}$

Single vs multi-institutional

Single institution

Multi-institutional

Type of study

Criteria for resectability

Retrospective series
Phase 2 studies
Prospective series
Phase 1 studies
Phase $1 / 2$ studies
Phase 3 studies

NCCN/AHPBA/SSO/SSAT consensus
MD Anderson
Other
Not mentioned
studies of each local/anatomical stag
Resectable
Borderline resectable (BR)
Locally advanced unresectable (LA)
$R+B R$
$B R+L A$
$R+B R+L A$

Number of patients in each anatomical stage

Resectable
Borderline resectable (BR)
Locally advanced unresectable (LA)
$R+B R$
$B R+L A$

Number of studies of each local/anatomical stage
Table 1 Summary of studies included in the quantitative analysis (Continued)

\begin{tabular}{lll}
\hline R + BR + LA & 473 & 8.6 \\
Criteria for of radiology response assessment & & \\
RECIST & 48 & 50 \\
WHO & 5 & 5.2 \\
Other & 2 & 2.1 \\
Not mentioned & 41 & 42.7 \\
Criteria for toxicity assessment & & \\
NCI CTCAE & 43 & 44.8 \\
WHO & 5 & 5.2 \\
RTOG & 2 & 2.1 \\
Not mentioned/not applicable & 46 & 47.9
\end{tabular}

Type of neoadjuvant therapy

$\begin{array}{lll}\text { Chemoradiotherapy } & 33 & 34.4 \\ \text { Chemotherapy alone } & 20 & 20.8 \\ \text { Chemotherapy with chemoradiation } & 41 & 42.7 \\ \text { Radiation alone } & 2 & 2.1\end{array}$

Chemotherapy drugs

\begin{tabular}{lll} 
Monotherapy (Gem/5FU/Cape/UFT/Cis) & 26 & 27.1 \\
FOLFIRINOX & 20 & 20.8 \\
Gemcitabine + oxaliplatin* & 8 & 8.3 \\
Gemcitabine or 5FU + cisplatin & 7 & 7.3 \\
Gemcitabine + Docetaxel & 3 & 3.1 \\
GTX (gemcitabine, taxane, capecitabine) & 6 & 6.3 \\
Gem + biologic (bevacizumab, cetuximab) & 3 & 3.1 \\
Gem + S1 & 5 & 5.2 \\
Gem + Nab-paclitaxel & 2 & 2.1 \\
5FU + cisplatin + interferon & 1 & 1 \\
Multiple & 11 & 11.5 \\
Not mentioned & 2 & 2.1 \\
None & 2 & 2.1 \\
Ypy & & \\
Yes & 76 & 79.2 \\
No & 20 & 20.8 \\
\hline
\end{tabular}

*Includes one study with gemcitabine + oxaliplatin + cetuximab $R$ resectable, $B R$ borderline resectable, $L A$ locally advanced, Gem Gemcitabine, Cape capecitabine, SFU 5 Fluorouracil, UFT uracil/tegafur

\section{Statistical methods}

Summary statistics are reported as total and percentages for categorical variables vs mean or median with corresponding standard deviation or ranges, respectively, for continuous variables. Meta-analysis was performed using STATA 14.2 statistical software (StataCorp, 4905 Lakeway Drive, College Station, Texas). Meta-analysis of proportions strategy using the command "metaprop" was utilized. Pooled estimates of proportions with corresponding 


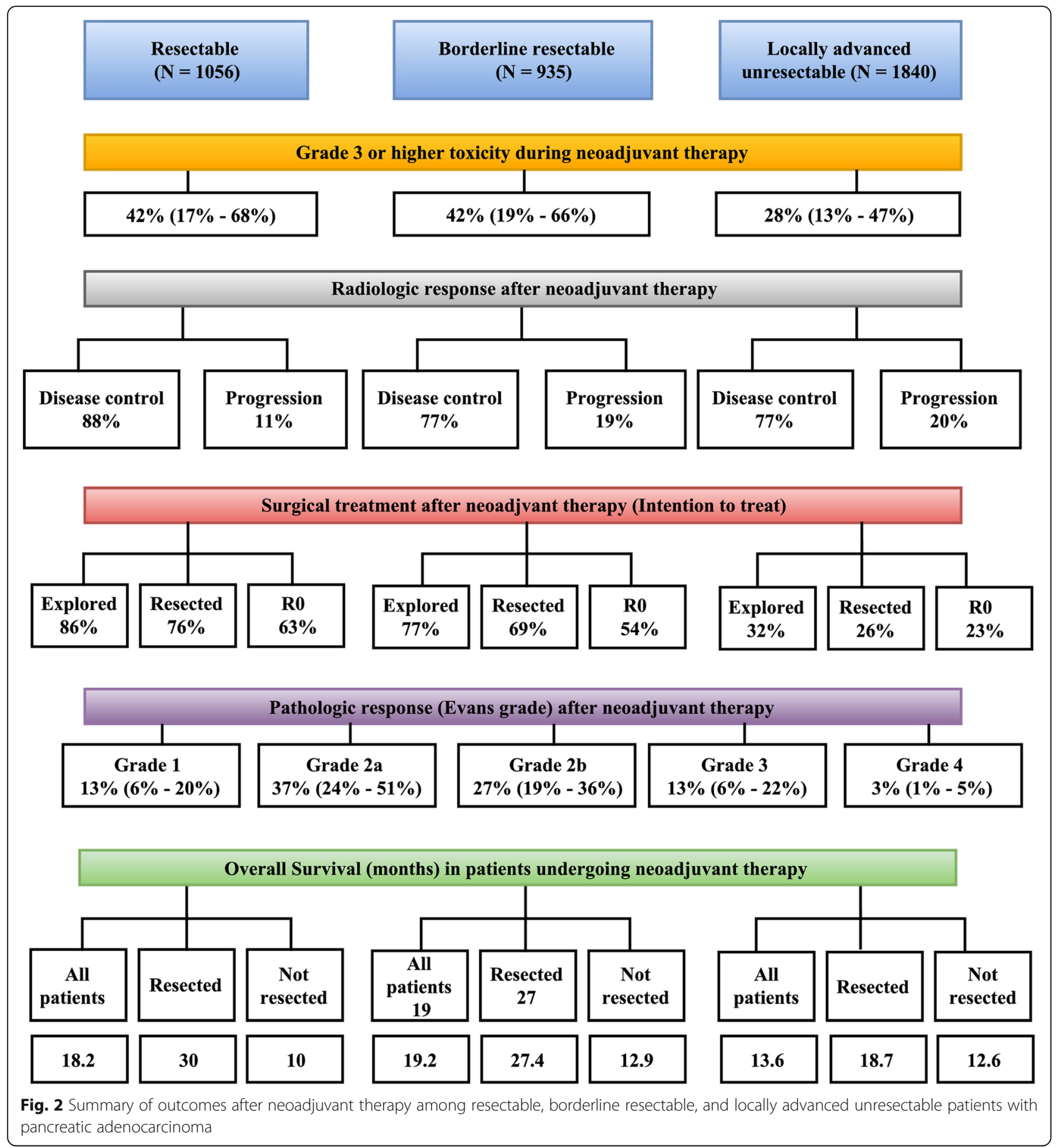

95\% confidence intervals were reported and calculated using Freeman-turkey double arcsine transformation [27]. Random effects model was used due to our suspicion of heterogeneity among different studies. Heterogeneity was explored using the chi-squared test with a significance level of $p=0.05$. $I^{2}$ was calculated to further quantify heterogeneity. Publication bias was explored using funnel plots and symmetry of the funnel plot was analyzed using visual inspection and Begg's tests to rule out any bias from the studies with small patient samples $[28,29]$. Additionally, subset analyses were used wherever feasible. The weighted aggregated median survival times were generated using SAS software, Version 9.4 (SAS Institute Inc., Cary, NC, USA). Since most studies only supplied median survival times and no additional information, i.e., patients at risk, confidence intervals, hazard ratios, etc. were consistently 
Table 2 Grade 3 or higher toxicities, readmission rates and mortality during the neoadjuvant treatment of patients with pancreatic adenocarcinoma

\begin{tabular}{llll}
\hline $\begin{array}{l}\text { Grade } 3 \text { or higher } \\
\text { toxicities }\end{array}$ & $\begin{array}{l}\text { Number of } \% \\
\text { studies } \\
\text { reporting } \\
\text { the studied } \\
\text { outcome }\end{array}$ & $\begin{array}{l}95 \% \text { confidence } \\
\text { interval }\end{array}$ \\
\hline Overall & 39 & $36 \%$ & $27-45 \%$ \\
Hematologic & 16 & $25 \%$ & $14-38 \%$ \\
Anemia & 33 & $4 \%$ & $3-6 \%$ \\
Leukopenia & 26 & $25 \%$ & $18-32 \%$ \\
Lymphopenia & 8 & $13 \%$ & $4-24 \%$ \\
Neutropenia & 38 & $23 \%$ & $17-29 \%$ \\
Febrile neutropenia & 17 & $3 \%$ & $1-5 \%$ \\
Thrombocytopenia & 41 & $7 \%$ & $5-10 \%$ \\
Non hematologic & 17 & $16 \%$ & $7-27 \%$ \\
Nausea/vomiting & 40 & $7 \%$ & $4-10 \%$ \\
Diarrhea & 38 & $4 \%$ & $2-6 \%$ \\
Anorexia & 19 & $3 \%$ & $1-6 \%$ \\
Fatigue & 26 & $4 \%$ & $1-7 \%$ \\
Biliary obstruction/cholangitis & 22 & $5 \%$ & $3-7 \%$ \\
Gl bleed, gastritis, or duodenitis, & 14 & $3 \%$ & $1-7 \%$ \\
Hospitalization rate & 15 & $21 \%$ & $14-27 \%$ \\
\% of patients completing & 42 & $90 \%$ & $87 \%-93 \%$ \\
neoadjuvant therapy & 48 & $0 \%$ & $0-1 \%$ \\
Mortality & & & \\
\hline
\end{tabular}

available, we used the method described by Gillen et al. to weight and aggregate the median survival times [23]. Briefly, $w_{i}$ denotes the weight of an individual study which is calculated as $n / N$ where $n$ is the number of study participants, and $\mathrm{N}$ is the total number of evaluable patients within a stratum. If $m_{i}(i=1, \ldots, k)$ represents the median survival time of an individual study within a stratum, then a weighted estimate of the median survival of the stratum $\left(m_{s}\right)$ can be calculated as follows.

$$
m_{s}=\left(\sum_{i=1}^{k} \frac{w_{i}}{m_{i}}\right)^{-1} \text { where } \sum w_{i}=1 \text {. }
$$

Confidence intervals cannot be computed using the method described by Gillen et al. [23]. Instead, Gillen et al. recommend reporting the minimum and maximum median survival times. [23]

\section{Results}

\section{Patient and study characteristics}

A total of 96 studies [30-125] including 82 original articles and 14 abstracts including 5520 patients, were selected for qualitative and quantitative synthesis. These include 1056 patients with resectable tumors, 935 with borderline resectable tumors, and 1840 with locally advanced unresectable tumors, with an additional 1689 patients in overlapping categories. Most of the studies were retrospective series but 22 phase II studies were also included in the current analysis. Sixty-five percent of the included studies were from 2013 to 2015. Majority (78.1\%) of the studies mentioned resectability criteria. Majority of the included studies were single institutional (86.5\%) and majority were from institutions located in North America and Europe (78.2\%). Chemotherapy alone was used in 20 (20.8\%) studies, chemoradiotherapy in 33(34.4\%) studies, chemotherapy with chemoradiation was used in 41 (42.7\%), and radiation alone was used in 2 (2.1\%) studies. Type of chemotherapy agent utilized included FOLFIRINOX in 810 patients, GTX in 410 patients, single drug (gemcitabine/5FU/capecitabine) in 1521 patients, two-drug regimen (gem + cisplatin/nabpaclitaxel/oxaliplatin/bevacizumab/docetaxel/S1) in 1113 patients or three drug combinations other than FOLFIRINOX or GTX in 60 patients. Studies with 1198 patients described use of multiple regimes whereas 222 patients had RT alone and in 186 patients chemotherapy agent was not described. Table 1 provides a summary of major characteristics of the included studies and Additional file 1: Table S1 provides details on all the included studies. Figure 2 provides a snapshot and Tables 1 through 5 provide details of results which are also elaborated below.

\section{Toxicity}

Only grade $\geq 3$ toxicities were analyzed. Data regarding any form of grade $\geq 3$ toxicity were available in 55 of the 96 studies. Details regarding toxicity are summarized in Table 2 . Briefly, overall grade $\geq 3$ toxicity was seen in $36 \%$ of the patients (95\% CI 27-45\%). Hematologic grade $\geq 3$ toxicity was more common than nonhematologic grade $\geq 3$ toxicity ( 25 vs $16 \%$ ). One-fifth of all patients receiving therapy were hospitalized during the neoadjuvant therapy. Over $90 \%$ of the patients were able to complete majority of the neoadjuvant treatment (not considering dose reductions). Most studies reported a mortality rate of $0 \%$ (95\% CI $0-1 \%)$. Funnel plots for overall grade $\geq 3$ toxicity are reported in Additional file 3 : Figure S1. No statistically significant publication bias was noted using Begg's test $(p=0.572)$ and Egger's test $(p=0.293)$.

A subset analysis was performed for overall grade $\geq 3$ toxicities for studies utilizing NCI CTCAE criteria. Again overall grade $\geq 3$ toxicity was noted in $36 \%$ of the patients (95\% CI 24-48\%). Pooled estimates for studies utilizing NCI CTCAE criteria were similar to those obtained for all studies reporting overall grade $\geq 3$ toxicities. Figure 3 depicts the forest plot for overall grade $\geq 3$ toxicities in the studies utilizing NCI CTCAE criteria. 


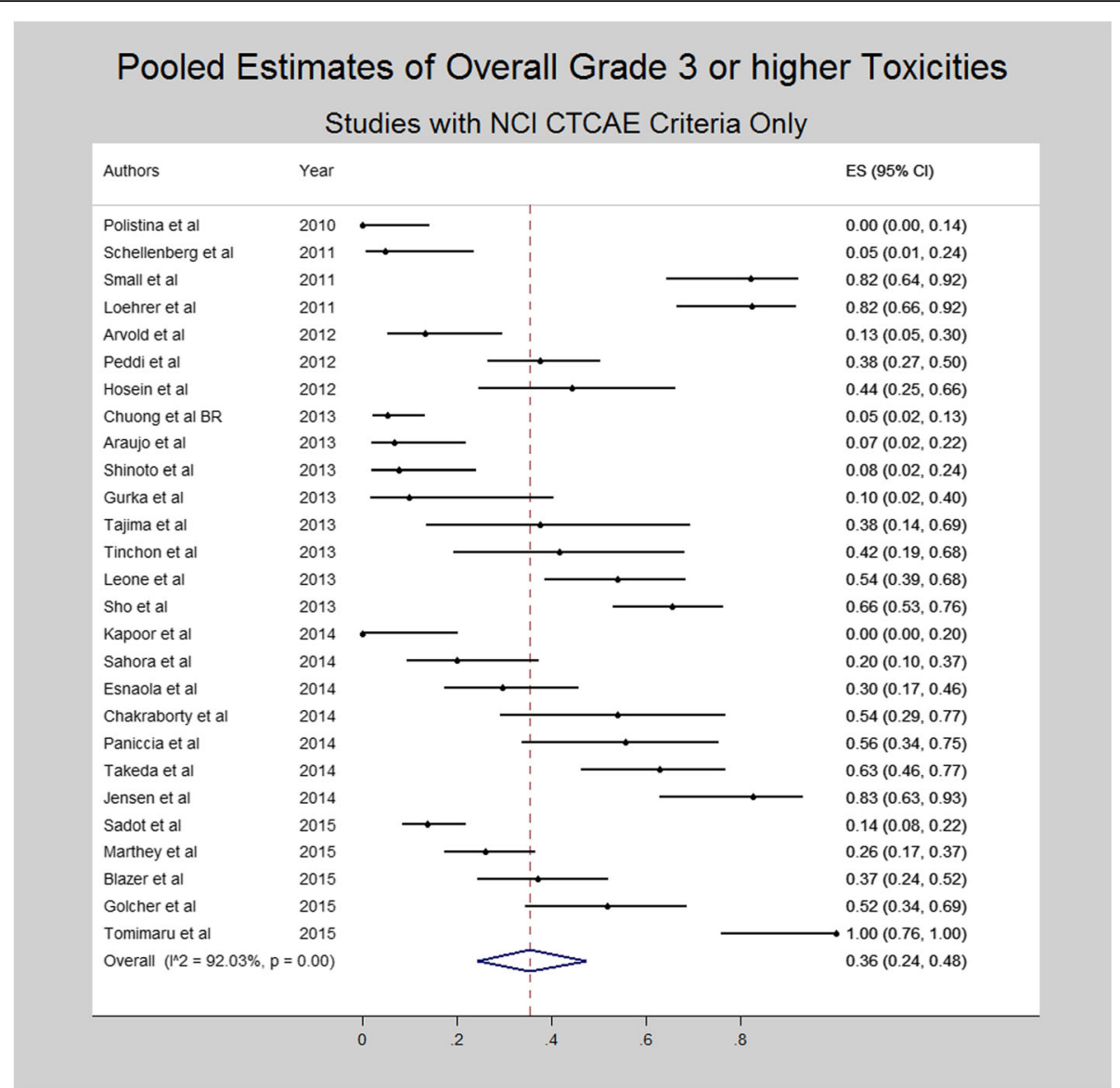

Fig. 3 Forest plot depicting pooled estimates for overall grade $\geq 3$ toxicities among studies utilizing $\mathrm{NCI} C \mathrm{CTCAE}$ criteria for toxicity assessment during neoadjuvant therapy

\section{Radiologic response}

The results for radiologic response by broad categories (disease control and progression) are outlined in Fig. 2, whereas the complete details of radiologic response (complete response, partial response, stable disease and progressive disease) are highlighted in Table 3. Tumor response was evaluated in 61 studies prior to resection, however not all studies mentioned all response categories including complete response, partial response, stable disease and progressive disease. As previously reported, the incidence of complete response was between $0-1 \%$. Overall partial response was seen in $20 \%$ (95\% CI $16-$ $25 \%$ ). Most patients had stable disease 59\% (95\% CI 54$65 \%)$. Overall progressive disease during neoadjuvant therapy was noted in 16\% (95\% CI 12-20\%) of patients.

In patients with resectable tumors, there were no complete radiologic responses. Partial response was seen in $11 \%$ of patients and majority (77\%) had stable disease. Progression was noted in $11 \%$ of the patients. In patients with borderline resectable tumors, 20\% had partial response, $56 \%$ had stable disease and 19\% progressed during therapy. In patients with locally advanced disease, $1 \%$ had complete response, $28 \%$ had partial response, $48 \%$ stable disease, and $20 \%$ experienced progression after neoadjuvant therapy. Stable disease was the predominant pattern across all disease categories. Funnel plots are depicted in Additional file 3: Figures. S2 thru S4. Although funnel plots were found to be symmetric on visual inspection, small study effects were more pronounced for stable disease (Begg's test $p=1$, Egger's test $p=0.02$ ) and progressive disease analyses (Begg's test $p=0.135$, Egger's test $p=0.033$ )

Subset analysis was performed for studies utilizing the NCCN/AHPBA/SSO/SSAT criteria for resectability and RECIST criteria for radiologic response (Figs. 4, 5, and 6). Similar to the results of all studies, subset analysis revealed an overall complete response of $0 \%(0-1 \%)$ including $0 \%$ (95\% CI $0-0 \%$ ) for resectable disease, $1 \%$ (95\% CI 0-4\%) for borderline resectable and 1\% (95\% CI 0-3\%) for locally advanced disease. Similarly, rates of partial response were $14 \%$ (95\% CI 11-19\%) for resectable, $30 \%$ (95\% CI 18\% - 43\%) for borderline resectable 
Table 3 Radiologic response after completion of neoadjuvant therapy for patients with pancreatic adenocarcinoma

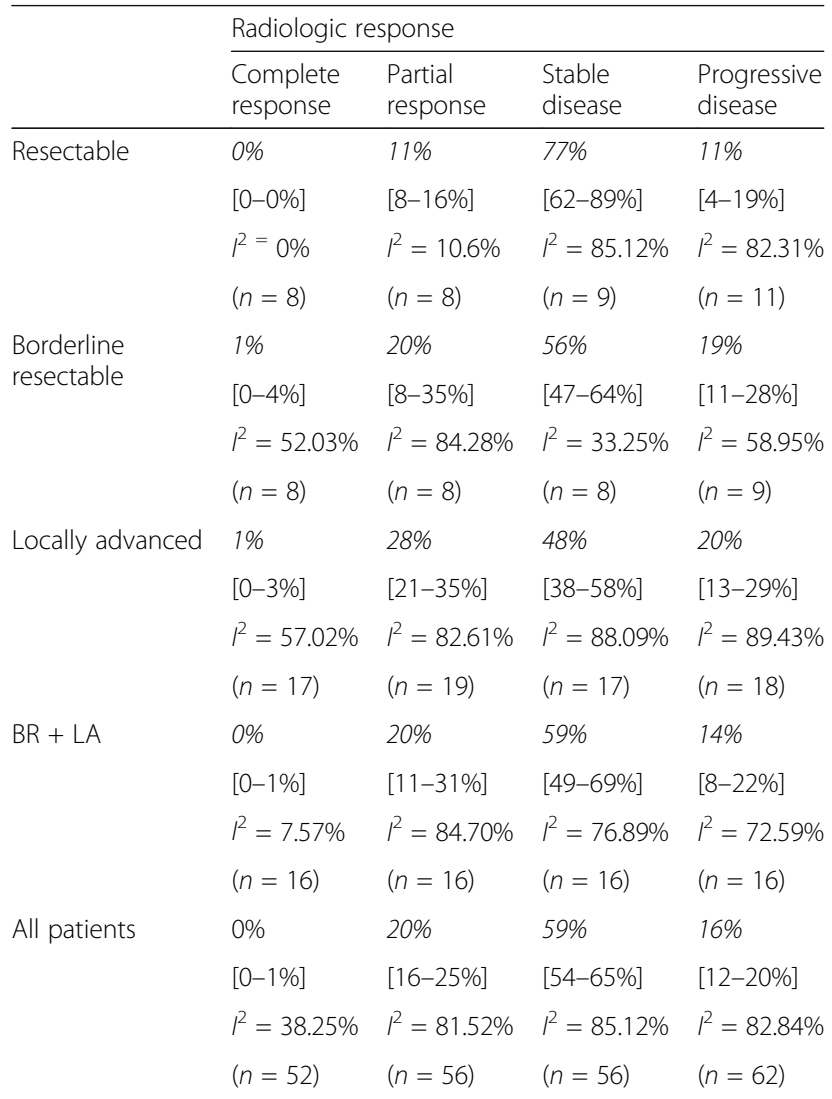

Values in [] reflect the $95 \%$ confidence interval. $I^{2}$ is a quantitative indicator of heterogeneity among the studies, and $n$ refers to the number of studies reporting the outcomes

and 24\% (95\% CI 11-40\%) for locally advanced patients. Rates of stable disease were $81 \%$ (95\% CI 76-85\%), 55\% (95\% CI 43-66\%) and 55\% (95\% CI 34-75\%) for resectable, borderline resectable, and locally advanced patients, respectively. Rates of progressive disease varied, being $3 \%$ (95\% CI 1-5\%) for resectable disease, 12\% (95\% CI 7-18\%) for borderline resectable, and $21 \%$ (95\% CI 5$42 \%$ ) for locally advanced patients.

\section{Exploration and resection rates}

Figure 2 provides a summary and Table 4 provides details of the surgical resection rates after neoadjuvant therapy for pancreatic adenocarcinoma. Exploration and resection rates were calculated on an intention-to-treat basis, i.e., denominator included all patients who underwent neoadjuvant therapy. These data were available for most included studies. Exploration rates varied by the disease category, i.e., resectable (86\%), borderline resectable $(77 \%)$ and locally advanced (32\%). As expected, the highest resection rates were noted for resectable patients (76\%), followed by borderline resectable (69\%), and locally advanced disease (26\%). R0 resection rates were $63 \%$ for resectable patients, $54 \%$ for borderline resectable, and $23 \%$ for locally advanced disease on an intention-to-treat basis. For all patients in all categories who were selected for resection after neoadjuvant therapy, $85 \%$ had R0 resection. Funnel plots are depicted in Additional file 3:Figures S5 thru S6. No significant small study effects were noted for exploration (Begg's test $p=0.234$, Egger's test $p=0.085$ ) and resection rates (Begg's test $p=0.528$, Egger's test $p=0.457)$.

Subset analysis for resection rates was performed for studies utilizing the NCCN/AHPBA/SSO/SSAT criteria for resectability (Fig 7). Resection rates on an intention to treat basis were $80 \%$ for resectable patients $(95 \% \mathrm{CI}$ 53-98\%), 70\% for borderline resectable patients (95\% CI $59-80 \%)$ and $32 \%$ for locally advanced patients (95\% CI $19-46 \%)$.

\section{Pathologic response}

Figure 2 provides a summary and Additional file 2: Table S2 provides details of the pathologic responses after neoadjuvant therapy. Pathologic grading of the tumor response was available in 36 studies. The Evans grading system was used in 16 studies. Regardless of the pathologic grading system used, if complete pathologic responses were reported, they were counted as grade 4 Evans responses and $>90 \%$ tumor destruction was considered grade 3 . For further analysis we focused on the Evans grading system for response to neoadjuvant therapy. Grade $2 \mathrm{a}(37 \%)$ or $2 \mathrm{~b}(27 \%)$ were the predominant histopathologic response types. Funnel plots were not generated given small number of studies. There is risk of bias with these calculations given the limitation of small number of studies which reported Evans criteria.

\section{Surgical morbidity and mortality}

The overall morbidity was calculated for all patients undergoing exploration whereas grade 3 or higher morbidity was calculated for patients who underwent resection. Twenty eight studies reported the morbidity rates and 41 studies reported the perioperative mortality rates. Overall morbidity, grade 3 or higher morbidity and perioperative mortality rates were 39\% (95\% CI 33$45 \%), 18 \%(13-23 \%)$ and $1 \%(0-2 \%)$, respectively. Funnel plots are depicted in Additional file 3: Figures S7 and S8. No significant small study effects were noted (Begg's test and Egger's test $>0.05$ ).

\section{Overall survival}

A meta-analysis of the median OS and PFS was performed using the strategy proposed by Gillen et al. [23] Fig. 2 provides a summary and Table 5 provides details of median OS for all patients stratified by the extent of the disease and resection status. Pooled median OS in studies with single-agent chemotherapy (gemcitabine, 5- 


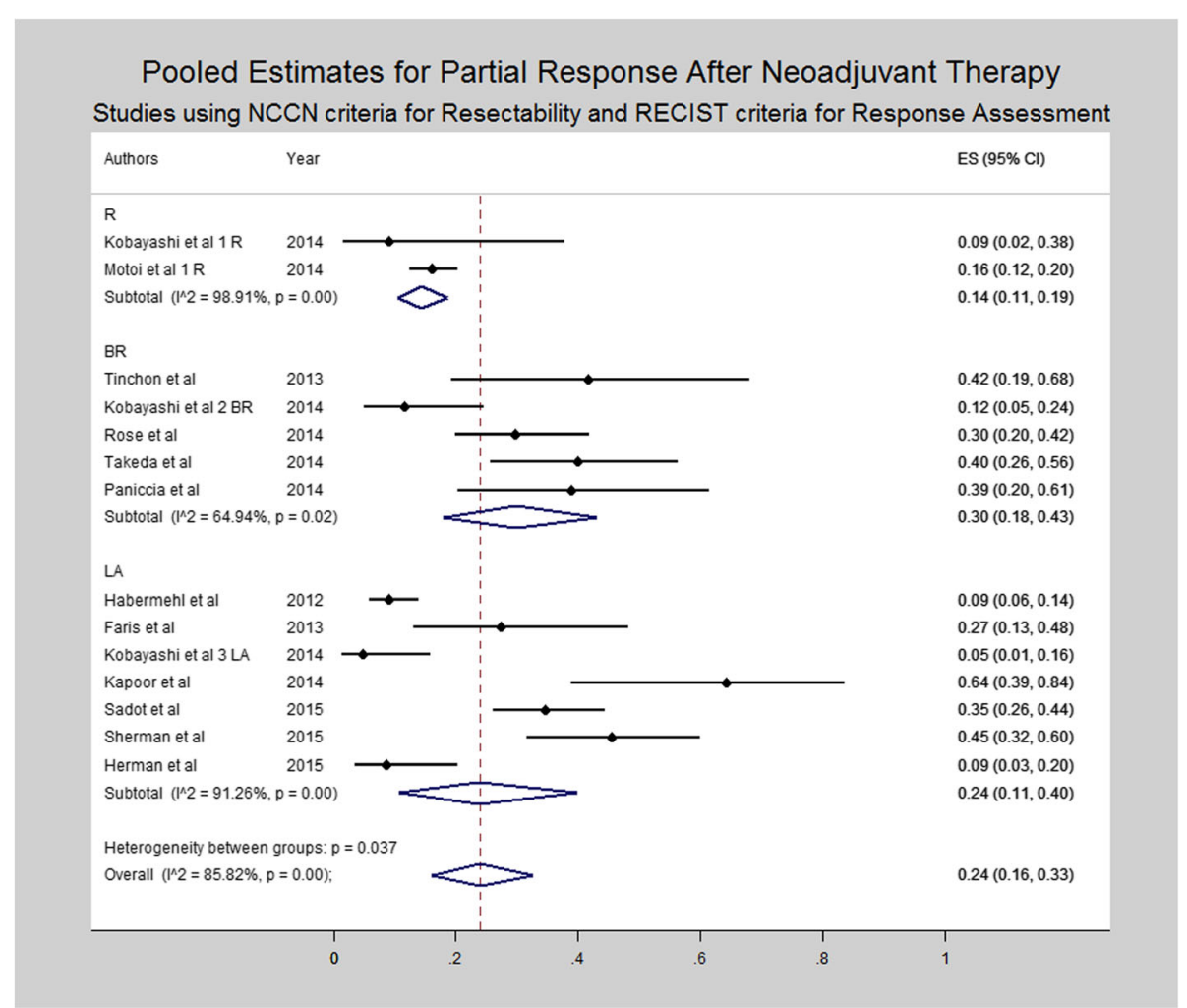

Fig. 4 Forest plots depicting pooled estimates for partial response at the time of restaging during or after neoadjuvant therapy. Only studies utilizing NCCN or AHBPA/SSO/SSAT criteria were included in the forest plot

fluorouracil, or capecitabine) was 14.7 months (range 9.1-47 months). Studies with two drug regimens were noted to have a pooled median OS of 16.1 months (range 7.3-45 months). Pooled median OS was longest in the studies utilizing FOLFIRINOX with median OS of 22.1 months (range 16.7-34 months) followed by GTX (Gemcitabine, Taxane, Capecitabine) at 19.4 months (range 15.6-25 months). Funnel plots were not generated as a different methodology as previously reported by Gillen et al. was utilized.

\section{Discussion}

With the expert consensus statement guidelines released in 2009, providing a uniform foundation was created for categorizing non-metastatic pancreatic adenocarcinoma into resectable, borderline resectable, and locally advanced disease. Given the overall poor prognosis of pancreatic adenocarcinoma, neoadjuvant therapy is being increasingly studied in the treatment of pancreatic adenocarcinoma across all anatomic categories including resectable, borderline resectable, and locally advanced disease. In recent years, we have seen several advancements with the introduction of newer chemotherapeutic regimens (FOLFIRNOX and gemcitabine-nab-paclitaxel) and their integration into the neoadjuvant therapeutic paradigm.
The current review was undertaken to summarize the outcomes for neoadjuvant therapy in pancreatic adenocarcinoma post-2009 which marks the release of the consensus statements as well as the introduction of newer neoadjuvant regimens. Integrating the breakdown of pancreatic adenocarcinoma by anatomic category with chemotherapy and surgical characteristics, the current analyses includes 5520 patients from 96 studies. The resulting data formulate a perspective on critical outcomes including toxicities, responses, surgical, and survival characteristics that can help guide patients and physicians.

One concern of neoadjuvant therapy is that possible toxicities might contribute to patient morbidity or mortality. Grade $\geq 3$ toxicities were seen in $36 \%$ of patients with a higher incidence of grade $\geq 3$ hematologic (25\%) than non-hematologic toxicity (16\%); however, mortality during neoadjuvant therapy was low $(95 \%$ CI $0-1 \%)$. The hospitalization rate during neoadjuvant therapy was $21 \%$. Our data suggest that these toxicities were manageable since majority of patients $(91 \%)$ were able to complete neoadjuvant therapy as reported in 42 studies (not considering dose modifications).

Neoadjuvant therapy remains most controversial for patients with resectable pancreatic adenocarcinoma. 


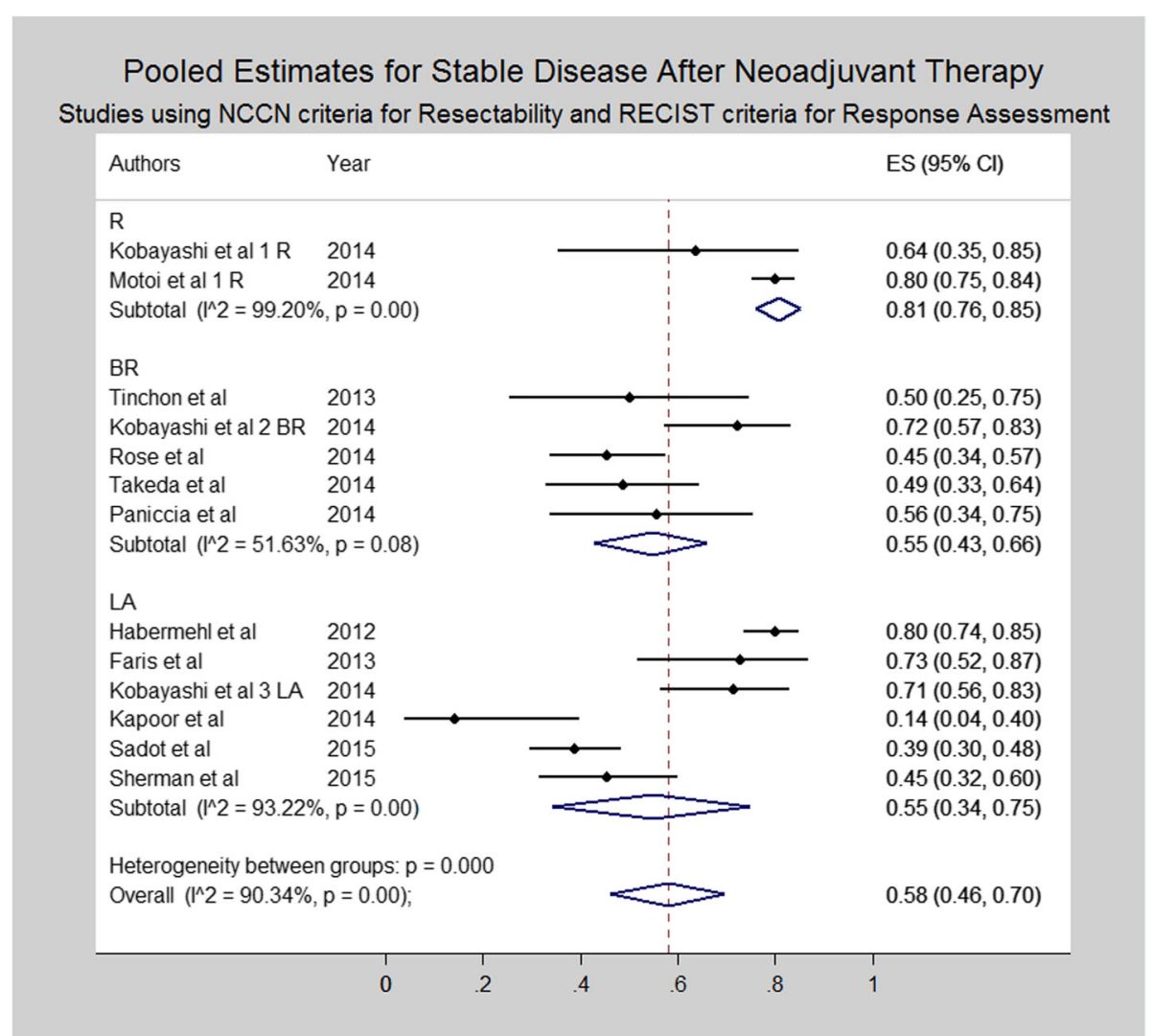

Fig. 5 Forest plots depicting pooled estimates for stable disease at the time of restaging during or after neoadjuvant therapy. Only studies utilizing NCCN or AHBPA/SSO/SSAT criteria were included in the forest plot

Critics of the neoadjuvant approach have cited disease progression, patient anxiety, and lack of proven benefit of neoadjuvant therapy in patients with resectable disease, whereas the proponents propose that neoadjuvant therapy allows testing of tumor biology and spares unnecessary surgery in patients who are destined to develop rapidly progressive metastatic disease in the immediate post-operative period. Stable disease remains the predominant radiologic response after neoadjuvant therapy. Progression was seen in a minority of patients (16\%) overall and in an even smaller proportion of patients with resectable disease (11\%). Surgical morbidity and mortality after neoadjuvant therapy remain acceptable with grade 3 or higher morbidity of $18 \%$ and mortality of $1 \%$. These are comparable to morbidity and mortality after upfront resection. These data suggest that progression during neoadjuvant therapy is rare and neoadjuvant therapy does not increase morbidity or mortality after surgery.

Although the main goal of any neoadjuvant strategy is to prolong survival, another goal is to improve R0 resection, as positive resection margins have been shown to be associated with worse survival [126-128]. Previous studies of adjuvant therapy have reported an $\mathrm{R} 1$ resection rate of $24-42 \%[126,127,129,130]$ whereas margin positive rate has been $<10 \%$ in previous trials of neoadjuvant therapy in selected centers $[131,132]$. In the current study, for patients (all disease categories) who were explored after neoadjuvant therapy, over $80 \%$ of the patients had R0 resection. Importantly, patients with resectable disease undergoing resection after the receipt of neoadjuvant therapy have high likelihood of margin negative resection with an improved estimated median survival of up to 30 months. Additionally, one could argue that R0 resection rate of $63 \%$ on an intention to treat basis may seem low-this is in par with previous surgical series reporting an $\mathrm{R} 1$ resection rate of $>30 \%$ including ESPAC 3 (R1 rate $=35 \%)[126,129,130]$. These data suggest that neoadjuvant therapy increases the likelihood of R0 resection among all anatomic subcategories of pancreatic adenocarcinoma.

In the current review, median OS for all patients with resectable disease who underwent neoadjuvant therapy was 18 months. Previous trials of adjuvant therapy have reported a median OS of approximately 20-23 months [129, 130, 133, 134]. However, the results are not 


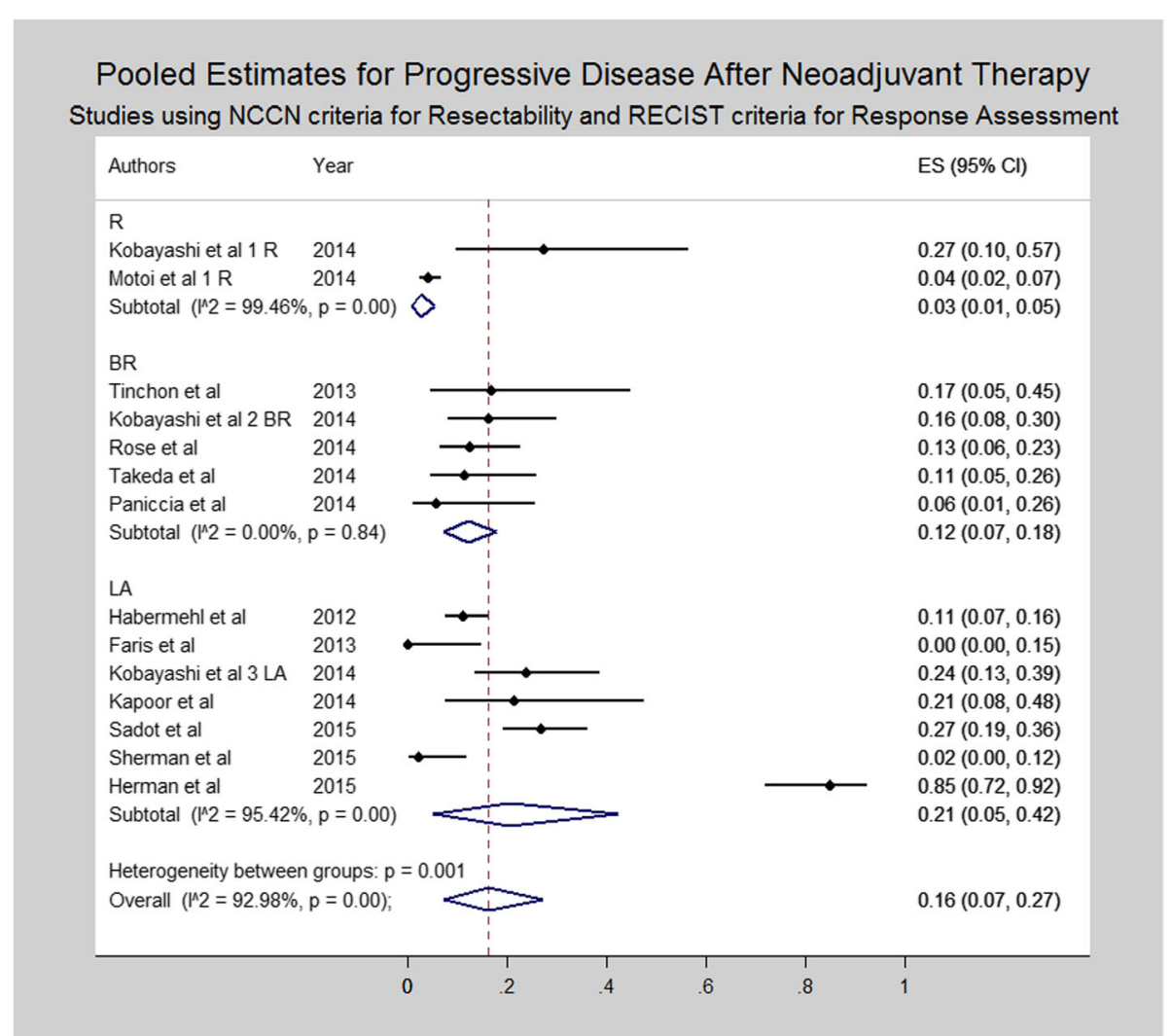

Fig. 6 Forest plots depicting pooled estimates for progressive disease at the time of restaging during or after neoadjuvant therapy. Only studies utilizing NCCN or AHBPA/SSO/SSAT criteria were included in the forest plot

comparable as the adjuvant therapy trials only included patients who were able to undergo resection, recovered well after surgery to undergo chemotherapy, and in some studies were required to not have metastatic disease on a postoperative scan [130]. Previous studies have suggested that only approximately $50-60 \%$ of the patients are able to receive adjuvant therapy after surgery [16-18]. In the current study, resectable patients who were able to undergo resection after neoadjuvant therapy had a median OS of up to 30 months. Median survival among those patients with resectable tumors who were unable to undergo resection for various reasons was only 10 months. It can be speculated that these patients might not have benefitted from upfront resection and might have developed rapidly progressive disease in the postoperative period. Conversely, NAT could have precluded these patients from undergoing a curative resection. Although adjuvant therapy can add some incremental prolongation of survival, surgery remains the only curative-intent treatment option. At this time upfront surgery followed by a combination of gemcitabine and capecitabine remains the standard of care for resectable pancreatic adenocarcinoma based on the results of ESPAC-4 trial [135]. In this phase 3, open label, randomized controlled trial median OS of patients in the gemcitabine plus capecitabine arm was 28 months compared to 25.5 months for gemcitabine alone (HR 0.82 , 95\% CI $0.68-0.98, p=0.032$. Neoadjuvant therapy for resectable pancreatic adenocarcinoma remains an area of active investigation. One of the ongoing trials S1505 conducted by Southwest Oncology Group (A randomized phase II study of perioperative mFOLFIRINOX vs. gemcitabine/nab-paclitaxel as therapy for resectable pancreatic adenocarcinoma, clinicaltrials.gov NCT02562716) is evaluating the role of newer multidrug regimens in neoadjuvant setting, in patients with resectable pancreatic adenocarcinoma, with a primary endpoint of OS. Such studies will shed further light on the effectiveness of neoadjuvant therapy in resectable pancreatic adenocarcinoma [136]. Additionally, all attempts should be made to study NAT in resectable pancreatic cancer in the context of clinical studies.

The role of neoadjuvant therapy in patients with borderline resectable pancreatic adenocarcinoma is well recognized [7]. Interestingly, for patients with locally advanced disease, $22 \%$ were eventually able to achieve an $\mathrm{R} 0$ resection in the current review. R0 resection rates were $82 \%$ in patients who underwent resection. A recent 
Table 4 Surgical exploration and resection rates after neoadjuvant therapy

\begin{tabular}{|c|c|c|c|c|c|}
\hline Surgical treatment & Explored/N & Resected/N & $\mathrm{RO} / \mathrm{N}$ & Resected/explored & Ro/resected \\
\hline \multirow[t]{4}{*}{ Resectable } & $86 \%$ & $76 \%$ & $63 \%$ & $92 \%$ & $88 \%$ \\
\hline & [79-92\%] & [68-84\%] & [51-75\%] & [85-97\%] & [80-94\%] \\
\hline & $R^{2}=83.91 \%$ & $P^{2}=86.02 \%$ & $R^{2}=90.69 \%$ & $R^{2}=83.37 \%$ & $P^{2}=81.82 \%$ \\
\hline & $(n=18)$ & $(n=18)$ & $(n=14)$ & $(n=18)$ & $(n=14)$ \\
\hline \multirow[t]{4}{*}{ Borderline resectable } & $77 \%$ & $69 \%$ & $54 \%$ & $91 \%$ & $84 \%$ \\
\hline & {$[66-86 \%]$} & [59-78\%] & [37-71\%] & [84-96\%] & [67-96\%] \\
\hline & $P^{2}=87.62 \%$ & $r^{2}=88.98 \%$ & $P^{2}=95.15 \%$ & $P^{2}=70.68 \%$ & $P^{2}=93.75 \%$ \\
\hline & $(n=15)$ & $(n=18)$ & $(n=16)$ & $(n=15)$ & $(n=16)$ \\
\hline \multirow[t]{4}{*}{ Locally advanced } & $32 \%$ & $26 \%$ & $23 \%$ & $86 \%$ & $82 \%$ \\
\hline & {$[23-42 \%]$} & [19-34\%] & [15-33\%] & [73-95\%] & [69-93\%] \\
\hline & $P^{2}=91.44 \%$ & $P^{2}=89.42 \%$ & $P^{2}=91.18 \%$ & $r^{2}=86.04 \%$ & $R^{2}=82.75 \%$ \\
\hline & $(n=22)$ & $(n=24)$ & $(n=18)$ & $(n=19)$ & $(n=15)$ \\
\hline \multirow[t]{4}{*}{$B R+L A$} & $65 \%$ & $53 \%$ & $39 \%$ & $89 \%$ & $85 \%$ \\
\hline & [49-79\%] & [36-70\%] & {$[27-52 \%]$} & [80-96\%] & [79-90\%] \\
\hline & $R^{2}=95.67 \%$ & $P^{2}=96.04 \%$ & $P^{2}=92.74 \%$ & $P^{2}=85.80 \%$ & $R^{2}=35.55 \%$ \\
\hline & $(n=20)$ & $(n=22)$ & $(n=20)$ & $(n=19)$ & $(n=19)$ \\
\hline \multirow[t]{4}{*}{ All patients } & $64 \%$ & $55 \%$ & $45 \%$ & $91 \%$ & $85 \%$ \\
\hline & [57\% - -71\%] & [48-62\%] & [38-52\%] & [87-94\%] & [80-89\%] \\
\hline & $R^{2}=95.27 \%$ & $P^{2}=95.34 \%$ & $R^{2}=94.94 \%$ & $P^{2}=84.53 \%$ & $R^{2}=85.05 \%$ \\
\hline & $(n=84)$ & $(n=90)$ & $(n=74)$ & $(n=79)$ & $(n=70)$ \\
\hline
\end{tabular}

Values in [] reflect the $95 \%$ confidence interval. $I^{2}$ is a quantitative indicator of heterogeneity among the studies, $n$ refers to the number of studies reporting the outcomes

meta-analysis based on FOLFIRINOX for locally advanced pancreatic cancer reported a similar resection rate of $25.9 \%$ and $\mathrm{R} 0$ resection rate of $78.4 \%$ [137]. As more effective chemotherapeutic regimens become available, more patients may be able to undergo resection and may experience improvement in OS. One such study (clinicaltrials.gov NCT 02839343, Alliance 021501) is investigating the role of pre-operative extended chemotherapy (mFOLFIRINOX pre-operatively and FOLFOX postoperatively) with or without hypofractionated radiation therapy in patients with borderline resectable pancreatic adenocarcinoma.

Our study has several limitations given the heterogeneity among studies, heterogeneity in the regimens, use of radiation in some studies, and varying duration and tolerability of treatments-however, this is an expected and inherent feature of any systematic review. Heterogeneity between the patient populations, chemotherapy regimens, etc. could account for wide confidence intervals for some of the reported outcomes. The lack of standardization in the surgical techniques and pathologic assessment of specimens also makes comparison across studies challenging. Ideally, a meta-analysis should be performed using individual patient data; however, individual patient data may not always be available or practical. Although meta-analysis may be superior to individual studies, its qualitative results need to be viewed carefully even when the analysis is performed on data quantitatively larger than singleinstitutional studies. An extensive forward and backward search was undertaken to ensure the completeness of literature along with abstracts of selected meetings. However, there is a possibility that some studies might have been missed.

In addition, although the consensus guidelines attempt to separate patients into three distinct categories ( $R, B R$ and LA), in practice there can be some overlap between the BR and LA categories. At the extremes of BR and LA, the distinction is wellcharacterized, but there are several patients where the distinction is not that obvious (for example patients with approximately 180 degree involvement of SMA). Thus, some of the comparisons in the studies between the different categories need to be interpreted with caution. It also needs to be borne in mind that the adoption of FOLFIRINOX and gemcitabine-nab paclitaxel regimens is relatively recent (2011 and 2013) with lack of robust randomized controlled data. Our study used the Evans criteria for pooling the estimates of pathologic response [138]. Although Evans criteria remain the most widely used pathologic criteria for response assessment, 


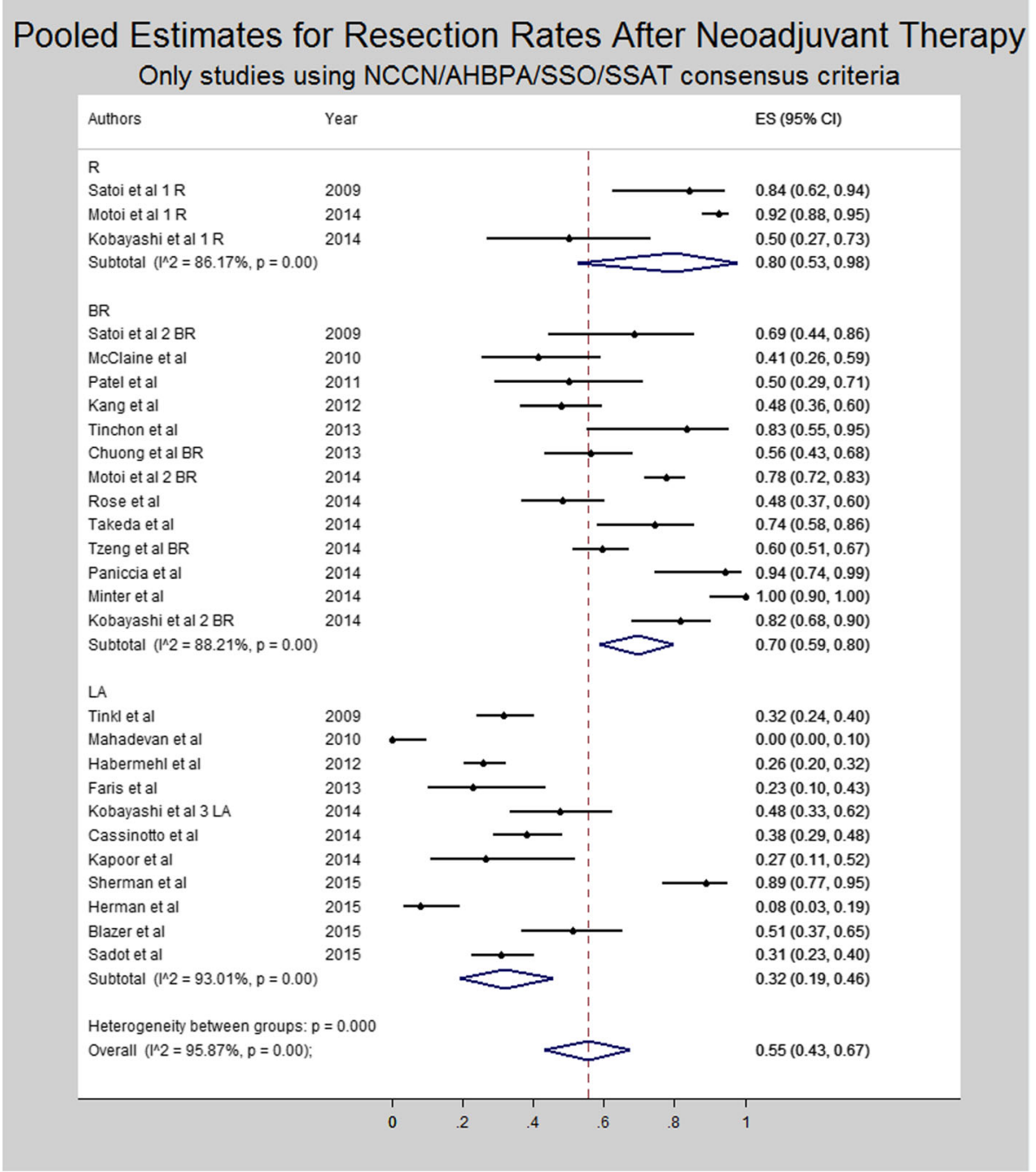

Fig. 7 Forest plot depicting pooled estimates for resection rates after neoadjuvant therapy. Only studies utilizing NCCN or AHBPA/SSO/SSAT criteria were included in the forest plot

these are not universally adopted [139]. Given the limitations of the current study, we could not perform a head to head comparison of morbidity and mortality of surgery followed by adjuvant therapy vs neoadjuvant therapy followed by surgery. Finally, the radiologic response rates may vary with the use of radiation therapy and also type of radiation therapy, i.e., IMRT vs SBRT. Response after chemoradiation may have different biological relevance than response after systemic chemotherapy alone. We could not decipher the effect of radiation given the differences in the duration, doses, and type of radiation treatments. In spite of its limitations, the current study provides a comprehensive summary of the data on neoadjuvant therapy for pancreatic adenocarcinoma and these data can be used for counseling at the time of informed consent for those patients interested in neoadjuvant therapy.

\section{Conclusions}

In conclusion, the current study reviewed data on 5520 patients with pancreatic adenocarcinoma (all stages of all non-metastatic disease: resectable, borderline resectable, and locally advanced) treated with neoadjuvant therapy and published in the last 7 years. The data summarize the surgical treatment, radiologic response, toxicity, pathologic response, morbidity and mortality as well survival of patients with pancreatic adenocarcinoma treated with neoadjuvant therapy. Although surgery first continues to be the standard of care and the only curative-intent treatment option for resectable disease, the results of this systematic review demonstrate increasing adoption of neoadjuvant therapy with some favorable outcomes. The introduction of more effective chemotherapeutic agents will help in increasing the 
Table 5 Summary of Median Overall Survivals in the various studies included in the current review

\begin{tabular}{|c|c|c|c|c|}
\hline & & \multicolumn{3}{|c|}{ Overall survival (months) } \\
\hline & & All patients & Resected & Not resected \\
\hline \multirow[t]{2}{*}{ Resectable } & Median (range) & $18.2(13-28)$ & $30.0(24.5-46)$ & $10(9-11)$ \\
\hline & $n$ & 9 & 8 & 5 \\
\hline \multirow[t]{2}{*}{ Borderline resectable } & Median (range) & $19.2(9.1-45)$ & $27.4(19.3-41.2)$ & $12.9(9-15.5)$ \\
\hline & $n$ & 11 & 8 & 7 \\
\hline \multirow[t]{2}{*}{ Locally advanced } & Median (range) & $13.6(7.3-32.5)$ & $18.7(14.4-24.9)$ & $12.6(8-19.7)$ \\
\hline & $n$ & 28 & 8 & 7 \\
\hline \multirow[t]{2}{*}{$B R+L A$} & Median (range) & $14.7(10.6-47.2)$ & $26(13-47.4)$ & $12.4(8.8-17)$ \\
\hline & $n$ & 16 & 11 & 9 \\
\hline \multirow[t]{2}{*}{ All patients } & Median (range) & $15.3(7.3-47.2)$ & $24.4(11.7-47.4)$ & $11.5(5.7-19.7)$ \\
\hline & $n$ & 63 & 39 & 32 \\
\hline \multicolumn{5}{|c|}{ Progression-free survival (months) } \\
\hline & & All patients & Resected & Not resected \\
\hline \multirow[t]{2}{*}{ Resectable } & Median (range) & $8.4(6.2-10.4)$ & $14.9(8.4-23)$ & $11^{*}$ \\
\hline & $n$ & 2 & 4 & 1 \\
\hline \multirow[t]{2}{*}{ Borderline resectable } & Median (range) & $9(2.4-21.1)$ & $15.4(4.7-23.2)$ & $2.1^{*}$ \\
\hline & $n$ & 6 & 6 & 1 \\
\hline \multirow[t]{2}{*}{ Locally advanced } & Median (range) & $9.3(4-17.6)$ & $12.9(9.6-22.5)$ & $5.7(4-8)$ \\
\hline & $n$ & 20 & 6 & 3 \\
\hline \multirow[t]{2}{*}{$B R+L A$} & Median (range) & $9.9(6.5-27.4)$ & $12.5(9-19.7)$ & $7.5(7.1-7.6)$ \\
\hline & $n$ & 9 & 4 & 2 \\
\hline \multirow[t]{2}{*}{ All patients } & Median (range) & $9.3(2.4-27.4)$ & $12.9(4.7-23.2)$ & $5.8(2.1-11)$ \\
\hline & $n$ & 31 & 20 & 7 \\
\hline
\end{tabular}

"Only one observation. $n$ number of studies reporting the outcome. Values in parenthesis indicate ranges

acceptance of neoadjuvant therapy in certain subpopulations. Ongoing therapeutic/clinical trials to test, validate and introduce newer and more effective chemotherapeutic agents will go a long way in tackling this lethal disease for which we may have reached the peak of our surgical expertise.

\section{Additional files}

Additional file 1: Table S1. Summary of studies included in current meta-analysis (DOCX 54 kb)

Additional file 2: Table S2. Pathologic response to neoadjuvant therapy (DOCX $17 \mathrm{~kb}$ )

Additional file 3: Funnel plots for assessment of publication bias and small study (PPTX $88 \mathrm{~kb}$ )

\section{Acknowledgements}

Not applicable

\section{Funding}

None

\section{Availability of data and materials}

The datasets used and/or analyzed during the current study are available from the corresponding author on request.
Authors' contributions

MD contributed to the conception and design, data collection, data analysis, and writing of the manuscript. GKM contributed to the conception and design, data collection, and critical review of the manuscript. DPSS contributed to the conception and design and critical review of the manuscript. NAH contributed to the data analysis and critical review of manuscript. LMS contributed to the data analysis and critical review of manuscript. EOR contributed to the conception and design and critical review of the manuscript. NB contributed to the conception and design, coordination, and critical review of the manuscript. CA contributed to the conception and design, data collection, supervision, coordination, and writing and critical review of the manuscript. All authors read and approved the final version of the manuscript.

Ethics approval and consent to participate

Not applicable as the current article is a review.

\section{Consent for publication}

Not applicable

Competing interests

The authors declare that they have no competing interests.

\section{Publisher's Note}

Springer Nature remains neutral with regard to jurisdictional claims in published maps and institutional affiliations. 


\section{Author details}

'Department of Surgery, SUNY Upstate Medical University, Syracuse, NY 13210, USA. ${ }^{2}$ Department of Surgery, University of Nebraska Medical Center, Omaha, NE 98198, USA. ${ }^{3}$ Division of Hematology and Oncology, Taussig Cancer Institute, Cleveland Clinic, Cleveland, OH 44195, USA. ${ }^{4}$ Department of Biostatistics, College of Public Health, University of Nebraska Medical Center, Omaha, NE 68198, USA. ${ }^{5}$ David M. Rubenstein Center for Pancreatic Cancer, Memorial Sloan Kettering Cancer Center, New York, NY 10065, USA. ${ }^{6}$ Department of Medicine, Division of Hematology and Oncology, University of Pittsburgh Medical Center, Pittsburgh, PA 15232, USA. ${ }^{7}$ Department of Surgery, Division of Surgical Oncology, University of Nebraska Medical Center, Omaha, NE 98198, USA. ${ }^{8}$ Department of Surgery/Genetics, Cell Biology and Anatomy, University of Nebraska Medical Center, Omaha, NE 68198, USA.

Received: 11 June 2017 Accepted: 25 August 2017

Published online: 10 October 2017

\section{References}

1. Siegel RL, Miller KD, Jemal A. Cancer statistics, 2017. CA Cancer J Clin. 2017:67:7-30

2. Conlon KC, Klimstra DS, Brennan MF. Long-term survival after curative resection for pancreatic ductal adenocarcinoma. Clinicopathologic analysis of 5-year survivors. Ann Surg. 1996;223:273-9.

3. National Cancer Institute Surveillance, Epidemiology and End Results Program SEER Stat Fact Sheets: Pancreas Cancer http://seercancergov/ statfacts/html/pancreashtml Accessed July 13, 2016.

4. Miller KD, Siegel RL, Lin CC, Mariotto AB, Kramer JL, Rowland JH, Stein KD, Alteri R, Jemal A. Cancer treatment and survivorship statistics, 2016. CA Cancer J Clin. 2016:66:271-89.

5. Abrams RA, Lowy AM, O'Reilly EM, Wolff RA, Picozzi VJ, Pisters PW. Combined modality treatment of resectable and borderline resectable pancreas cancer: expert consensus statement. Ann Surg Oncol. 2009;16:1751-6.

6. Callery MP, Chang KJ, Fishman EK, Talamonti MS, William Traverso L, Linehan DC. Pretreatment assessment of resectable and borderline resectable pancreatic cancer: expert consensus statement. Ann Surg Oncol. 2009:16:1727-33.

7. Tempero MA, Malafa MP, Behrman SW, Benson AB 3rd, Casper ES, Chiorean EG, Chung V, Cohen SJ, Czito B, Engebretson A, et al. Pancreatic adenocarcinoma, version 2.2014: Featured updates to the NCCN guidelines. J Natl Compr Cancer Netw. 2014;12:1083-93.

8. Burris HA 3rd, Moore MJ, Andersen J, Green MR, Rothenberg ML, Modiano MR, Cripps MC, Portenoy RK, Storniolo AM, Tarassoff P, et al. Improvements in survival and clinical benefit with gemcitabine as first-line therapy for patients with advanced pancreas cancer: a randomized trial. J Clin Oncol. 1997;15:2403-13.

9. Conroy T, Desseigne F, Ychou M, Bouche O, Guimbaud R, Becouarn Y, Adenis A, Raoul JL, Gourgou-Bourgade S, de la Fouchardiere C, et al. FOLFIRINOX versus gemcitabine for metastatic pancreatic cancer. N Engl J Med. 2011:364:1817-25.

10. Von Hoff DD, Ervin T, Arena FP, Chiorean EG, Infante J, Moore M, Seay T, Tjulandin SA, Ma WW, Saleh MN, et al. Increased survival in pancreatic cancer with nab-paclitaxel plus gemcitabine. N Engl J Med. 2013;369:1691-703.

11. Evans DB, Varadhachary GR, Crane CH, Sun CC, Lee JE, Pisters PW, Vauthey JN, Wang H, Cleary KR, Staerkel GA, et al. Preoperative gemcitabine-based chemoradiation for patients with resectable adenocarcinoma of the pancreatic head. J Clin Oncol. 2008:26:3496-502.

12. Katz MH, Pisters PW, Evans DB, Sun CC, Lee JE, Fleming JB, Vauthey JN, Abdalla EK, Crane $\mathrm{CH}$, Wolff RA, et al. Borderline resectable pancreatic cancer: the importance of this emerging stage of disease. J Am Coll Surg. 2008:206:833-46. discussion 846-838

13. Varadhachary GR, Wolff RA, Crane CH, Sun CC, Lee JE, Pisters PW, Vauthey JN, Abdalla E, Wang H, Staerkel GA, et al. Preoperative gemcitabine and cisplatin followed by gemcitabine-based chemoradiation for resectable adenocarcinoma of the pancreatic head. J Clin Oncol. 2008:26:3487-95.

14. Goldstein D, El-Maraghi RH, Hammel P, Heinemann V, Kunzmann V, Sastre J, Scheithauer W, Siena S, Tabernero J. Teixeira L, et al: nab-Paclitaxel plus gemcitabine for metastatic pancreatic cancer: long-term survival from a phase III trial. J Natl Cancer Inst. 2015;107

15. Bednar F, Zenati MS, Steve J, Winters S, Ocuin LM, Bahary N, Hogg ME, Zeh $\mathrm{HJ}$ 3rd, Zureikat AH. Analysis of predictors of resection and survival in locally advanced stage III pancreatic cancer: does the nature of chemotherapy regimen influence outcomes? Ann Surg Oncol. 2017;24:1406-13.
16. Herman JM, Swartz MJ, Hsu CC, Winter J, Pawlik TM, Sugar E, Robinson R, Laheru DA, Jaffee E, Hruban RH, et al. Analysis of fluorouracil-based adjuvant chemotherapy and radiation after pancreaticoduodenectomy for ductal adenocarcinoma of the pancreas: results of a large, prospectively collected database at the Johns Hopkins Hospital. J Clin Oncol. 2008;26:3503-10.

17. Corsini MM, Miller RC, Haddock MG, Donohue JH, Farnell MB, Nagorney DM, Jatoi A, McWilliams RR, Kim GP, Bhatia S, et al. Adjuvant radiotherapy and chemotherapy for pancreatic carcinoma: the Mayo Clinic experience (19752005). J Clin Oncol. 2008;26:3511-6.

18. Parmar AD, Vargas GM, Tamirisa NP, Sheffield KM, Riall TS. Trajectory of care and use of multimodality therapy in older patients with pancreatic adenocarcinoma. Surgery. 2014;156:280-9.

19. Tsai S, Christians KK, Ritch PS, George B, Khan AH, Erickson B, Evans DB. Multimodality therapy in patients with borderline Resectable or locally advanced pancreatic cancer: importance of Locoregional therapies for a systemic disease. J Oncol Pract. 2016;12:915-23.

20. Sohal DP, Walsh RM, Ramanathan RK, Khorana AA. Pancreatic adenocarcinoma: treating a systemic disease with systemic therapy. J Natl Cancer Inst. 2014:106:dju011.

21. Andriulli A, Festa V, Botteri E, Valvano MR, Koch M, Bassi C, Maisonneuve P, Sebastiano PD. Neoadjuvant/preoperative gemcitabine for patients with localized pancreatic cancer: a meta-analysis of prospective studies. Ann Surg Oncol. 2012;19:1644-62.

22. Assifi MM, Lu X, Eibl G, Reber HA, Li G, Hines OJ. Neoadjuvant therapy in pancreatic adenocarcinoma: a meta-analysis of phase II trials. Surgery. 2011:150:466-73.

23. Gillen S, Schuster T, Meyer Zum Buschenfelde C, Friess H, Kleeff J. Preoperative/neoadjuvant therapy in pancreatic cancer: a systematic review and meta-analysis of response and resection percentages. PLoS Med. 2010:7:e1000267.

24. NIH U.S. National Library of Medicine-Key MEDLINE(R) Indicators. Available at: https://www.n/m.nih.gov/bsd/bsd_key.html Accessed: Dec 17, 2016.

25. Rosmarakis ES, Soteriades ES, Vergidis PI, Kasiakou SK, Falagas ME. From conference abstract to full paper: differences between data presented in conferences and journals. FASEB J. 2005;19:673-80.

26. Moher D, Liberati A, Tetzlaff J, Altman DG, Group P. Preferred reporting items for systematic reviews and meta-analyses: the PRISMA statement. Ann Intern Med. 2009;151:264-9. W264

27. Nyaga VN, Arbyn M, Aerts M. Metaprop: a Stata command to perform meta-analysis of binomial data. Arch Public Health. 2014;72:39.

28. Begg CB, Mazumdar M. Operating characteristics of a rank correlation test for publication bias. Biometrics. 1994:50:1088-101.

29. Egger M, Davey Smith G, Schneider M, Minder C. Bias in meta-analysis detected by a simple, graphical test. BMJ. 1997;315:629-34.

30. Alline $M$, Colombo PE, Quenet F, Jarlier M, Portales F, Llacer C, Fabre JM, Ychou M, Rouanet P. Surgical resectability after neo-adjuvant FOLFIRINOX for borderline or locally advanced pancreatic adenocarcinoma. ASCO Meeting Abstracts. 2015;33:421

31. Alagappan M, Pollom EL, von Eyben R, Kunz PL, Fisher GA, Ford JM, Poultsides GA, Visser BC, Norton JA, Kamaya A, et al. Pretreatment lab values to predict overall survival in patients with primary unresectable pancreatic adenocarcinoma treated with SBRT. ASCO Meeting Abstracts. 2015;33:433.

32. Barbour A, O'Rourke N, Samra JS, Haghighi KS, Kench J, Mitchell J, Pavlakis N, Burge ME, Fawcett J, Gananadha S, et al. A multicenter, phase II trial of preoperative gemcitabine and nab-paclitaxel for resectable pancreas cancer: the AGITG GAP study. ASCO Meeting Abstracts. 2015;33:387.

33. Blazer M, Wu C, Goldberg RM, Phillips G, Schmidt C, Muscarella P, Wuthrick E, Williams TM, Reardon J, Christopher Ellison E, et al. Neoadjuvant modified (m) FOLFIRINOX for locally advanced Unresectable (LAPC) and borderline Resectable (BRPC) Adenocarcinoma of the pancreas. Ann Surg Oncol. 2015;22:1153-9.

34. RFd C, Gil E, Moreira RB, RDA P, MPF A, Zanuncio P, Ferrigno R, Moraes P, Maluf FC, Buzaid AC, MRDS C. Induction FOLFIRINOX followed by chemoradiation with capecitabine for unresectable locally advanced pancreatic cancer (LAPC): preliminary data. ASCO Meeting Abstracts. 2015;33:458

35. Chllamma M, Cook N, Giby K, Dodd A, Wang L, Dhani NC, Hedley DW Moore MJ. FOLFIRINOX for advanced pancreatic cancer: the Princess Margaret experience. ASCO Meeting Abstracts. 2015;33:417.

36. Ferrone CR, Marchegiani G, Hong TS, Ryan DP, Deshpande V, McDonnell El, Sabbatino F, Santos DD, Allen JN, Blaszkowsky LS, et al. Radiological and surgical implications of Neoadjuvant treatment with FOLFIRINOX for locally 
advanced and borderline Resectable pancreatic cancer. Ann Surg. 2015;261:12-7.

37. Golcher H, Brunner BT, Witzigmann H, Marti L, Bechstein W-O, Bruns C, Jungnickel H, Schreiber S, Grabenbauer GG, Meyer T, et al. Neoadjuvant chemoradiation therapy with gemcitabine/cisplatin and surgery versus immediate surgery in resectable pancreatic cancer. Strahlenther Onkol. 2015;191:7-16

38. Hajj C, Huguet F, Wu AJ-C, O'Reilly EM, Winston C, Reidy DL, Allen PJ, Goodman KA. Intensity-modulated radiation therapy (IMRT) in patients with locally advanced pancreatic cancer (LAPC). ASCO Meeting Abstracts. 2015;33:377.

39. He J, Moningi S, Blair AB, Zaki A, Laheru DA, Cameron JL, Pawlik TM, Weiss $\mathrm{MJ}$, Wolfgang $\mathrm{CL}$, Herman JM. Surgical outcomes of patients with pancreatic cancer treated with stereotactic body radiation therapy. ASCO Meeting Abstracts. 2015;33:341.

40. Herman JM, Chang DT, Goodman KA, Dholakia AS, Raman SP, Hacker-Prietz A, lacobuzio-Donahue CA, Griffith ME, Pawlik TM, Pai JS, et al. Phase 2 multiinstitutional trial evaluating gemcitabine and stereotactic body radiotherapy for patients with locally advanced unresectable pancreatic adenocarcinoma. Cancer. 2015;121:1128-37.

41. Marthey L, Sa-Cunha A, Blanc JF, Gauthier M, Cueff A, Francois E, Trouilloud I, Malka D, Bachet JB, Coriat R, et al. FOLFIRINOX for locally advanced pancreatic Adenocarcinoma: results of an AGEO multicenter prospective observational cohort. Ann Surg Oncol. 2015;22:295-301.

42. Rashid OM, Pimiento JM, Springett GM, Malafa MP. Outcomes of a clinical pathway for borderline resectable pancreatic cancer. ASCO Meeting Abstracts. 2015;33:374.

43. Sadot E, Doussot A, O'Reilly EM, Lowery MA, Goodman KA, Do RKG, Tang LH, Gönen M, D'Angelica MI, DeMatteo RP, et al. FOLFIRINOX induction therapy for stage 3 pancreatic Adenocarcinoma. Ann Surg Oncol. 2015;22:3512-21.

44. Sherman WH, Chu K, Chabot J, Allendorf J, Schrope BA, Hecht E, Jin B, Leung D, Remotti H, Addeo G, et al. Neoadjuvant gemcitabine, docetaxel, and capecitabine followed by gemcitabine and capecitabine/radiation therapy and surgery in locally advanced, unresectable pancreatic adenocarcinoma. Cancer. 2015;121:673-80.

45. Tomimaru Y, Eguchi H, Satoh T, Tomokuni A, Asaoka T, Wada H, Marubashi S, Ogawa K, Takehara T, Mori M, et al. Feasibility of pre-operative chemoradiotherapy with gemcitabine to treat pancreatic cancer in patients with impaired renal function. Jpn J Clin Oncol. 2015;45:343-8.

46. Wang-Gillam A, Nywening TM, Sanford DE, Lockhart AC, Suresh R, Tan BR, Lim K-H, Sorscher S, Fowler K, Amin MA, et al. Phase IB study of FOLFIRINOX plus PF-04136309 in patients with borderline resectable and locally advanced pancreatic adenocarcinoma (PC). ASCO Meeting Abstracts. 2015;33:338.

47. Cassinotto C, Mouries A, Lafourcade J-P, Terrebonne E, Belleannée G, Blanc J-F, Lapuyade B, Vendrely V, Laurent C, Chiche L, et al. Locally advanced pancreatic Adenocarcinoma: reassessment of response with $\mathrm{CT}$ after Neoadjuvant chemotherapy and radiation therapy. Radiology. 2014;273:108-16.

48. Chakraborty S, Morris MM, Bauer TW, Adams RB, Stelow EB, Petroni G, Sanoff HK. Accelerated fraction radiotherapy with Capecitabine as Neoadjuvant therapy for borderline Resectable pancreatic cancer. Gastrointestinal Cancer Research : GCR. 2014;7:15-22.

49. Chao Y-J, Sy ED, Hsu H-P, Shan Y-S. Predictors for resectability and survival in locally advanced pancreatic cancer after gemcitabine-based neoadjuvant therapy. BMC Surg. 2014;14:72.

50. Chen KT, Devarajan K, Milestone BN, Cooper HS, Denlinger C, Cohen SJ, Meyer JE, Hoffman JP. Neoadjuvant Chemoradiation and duration of chemotherapy before surgical resection for pancreatic cancer: does time interval between radiotherapy and surgery matter? Ann Surg Oncol. 2014;21:662-9.

51. Christians KK, Tsai S, Mahmoud A, Ritch P, Thomas JP, Wiebe L, Kelly T, Erickson B, Wang H, Evans DB, George B. Neoadjuvant FOLFIRINOX for borderline Resectable pancreas cancer: a new treatment paradigm? Oncologist. 2014;19:266-74.

52. Combs SE, Habermehl D, Kessel KA, Bergmann F, Werner J, Naumann P, Jäger D, Büchler MW, Debus J. Prognostic impact of CA 19-9 on outcome after Neoadjuvant Chemoradiation in patients with locally advanced pancreatic cancer. Ann Surg Oncol. 2014;21:2801-7.

53. Cuneo KC, Chenevert TL, Ben-Josef E, Feng MU, Greenson JK, Hussain HK, Simeone DM, Schipper MJ, Anderson MA, Zalupski MM, et al. A pilot study of diffusion-weighted MRI in patients undergoing neoadjuvant chemoradiation for pancreatic cancer. Transl Oncol. 2014;7:644-9.

54. Eguchi H, Nagano H, Kobayashi S, Kawamoto K, Wada H, Hama N, Tomimaru Y, Akita H, Sakai D, Satoh T, et al. A phase I trial of combination therapy using gemcitabine and S-1 concurrent with full-dose radiation for resectable pancreatic cancer. Cancer Chemother Pharmacol. 2014;73:309-15.

55. Epelboym I, DiNorcia J, Winner M, Lee MK, Lee JA, Schrope BA, Chabot JA, Allendorf JD. Neoadjuvant therapy and vascular resection during Pancreaticoduodenectomy: shifting the survival curve for patients with locally advanced pancreatic cancer. World J Surg. 2014;38:1184-95.

56. Esnaola NF, Chaudhary UB, O'Brien P, Garrett-Mayer E, Camp ER, Thomas MB, Cole DJ, Montero AJ, Hoffman BJ, Romagnuolo J, et al. Phase 2 trial of induction gemcitabine, oxaliplatin, and cetuximab followed by selective capecitabine-based chemoradiation in patients with borderline resectable or unresectable locally advanced pancreatic cancer. Int J Radiat Oncol Biol Phys. 2014;88:837-44.

57. Gulati AP, Schreibman SM, Schrope B, Lee JA, Allendorf J, Chabot JA, Tsushima D, Mowatt KB, Oprescu A, Chu K, et al. Prospective phase II study of inoperable pancreatic adenocarcinoma with neoadjuvant gemcitabine, docetaxel, and capecitabine (GTX). ASCO Meeting Abstracts. 2014;32:274.

58. Hong TS, Ryan DP, Borger DR, Blaszkowsky LS, Yeap BY, Ancukiewicz M, Deshpande V, Shinagare S, Wo JY, Boucher Y, et al. A phase $1 / 2$ and biomarker study of preoperative short course chemoradiation with proton beam therapy and capecitabine followed by early surgery for resectable pancreatic ductal adenocarcinoma. Int J Radiat Oncol Biol Phys. 2014;89:830-8.

59. Ioka T, Katayama K, Ishida N, Sueyoshi H, Takada R, Yamai T, Fukutake N, Ashida R, Akita H, Takahashi H, et al. Phase I/II study of gemcitabine plus S-1 with concurrent radiotherapy in patients of unresectable locally advanced pancreatic cancer. ASCO Meeting Abstracts. 2014;32:261.

60. James ES, Yao X, Cong X, Stein S, Kaley K, Hahn C, Cha C, Salem RR, Hochster HS, Lacy J. Interim analysis of a phase II study of dose-modified FOLFIRINOX (mFOLFIRINOX) in locally advanced (LAPC) and metastatic pancreatic cancer (MPC). ASCO Meeting Abstracts. 2014;32:256.

61. Jensen EH, Armstrong L, Lee C, Tuttle TM, Vickers SM, Sielaff T, Greeno EW. Neoadjuvant interferon-based chemoradiation for borderline resectable and locally advanced pancreas cancer: a phase II pilot study. HPB (Oxford). 2014;16:131-9.

62. Kapoor R, Khosla D, Gupta R, Bahl A, Shukla AK, Sharma SC. Role of neoadjuvant concurrent chemoradiation in locally advanced unresectable pancreatic cancer: a feasibility study at tertiary care centre. Indian J Cancer. 2014;51:176-9.

63. Kharofa J, Tsai S, Kelly T, Wood C, George B, Ritch P, Wiebe L, Christians K, Evans DB, Erickson B. Neoadjuvant chemoradiation with IMRT in resectable and borderline resectable pancreatic cancer. Radiother Oncol. 113:41-6.

64. Kobayashi M, Mizuno S, Murata Y, Kishiwada M, Usui M, Sakurai H, Tabata M, li N, Yamakado K, Inoue H, et al. Gemcitabine-based chemoradiotherapy followed by surgery for borderline resectable and locally unresectable pancreatic ductal adenocarcinoma: significance of the CA19-9 reduction rate and intratumoral human equilibrative nucleoside transporter 1 expression. Pancreas. 2014;43:350-60.

65. Minter RM, Feng MU-S, Al-Hawary M, Shen J, Schipper MJ, Bednar F, Proctor E, Warner SG, Zalupski MM, Simeone DM. Effect of neoadjuvant chemoradiotherapy (nCRT) on survival in patients with borderline resectable (BR) pancreatic adenocarcinoma (PDA) with acceptable peri-operative morbidity. ASCO Meeting Abstracts. 2014;32:288.

66. Mizuma M, Motoi F, Ishida K, Fujishima F, Ottomo S, Oikawa M, Okada T, Shimamura H, Takemura S, Ono F, et al. Neoadjuvant chemotherapy with gemcitabine and S-1 for resectable and borderline pancreatic ductal adenocarcinoma: a prospective, multi-institutional, phase II trial. ASCO Meeting Abstracts. 2014;32:283.

67. Motoi F, Unno M, Takahashi H, Okada T, Wada K, Sho M, Nagano H, Matsumoto I, Satoi S, Murakami Y, et al. Influence of preoperative anti-cancer therapy on resectability and perioperative outcomes in patients with pancreatic cancer: project study by the Japanese Society of Hepato-Biliary-Pancreatic Surgery. Journal of Hepato-Biliary-Pancreatic Sciences. 2014;21:148-58.

68. O'Reilly EM, Perelshteyn A, Jarnagin WR, Schattner M, Gerdes H, Capanu M, Tang LH, LaValle J, Winston C, DeMatteo RP, et al. A single-arm, nonrandomized phase II trial of neoadjuvant gemcitabine and oxaliplatin in patients with resectable pancreas adenocarcinoma. Ann Surg. 2014;260:142-8.

69. Paniccia A, Edil BH, Schulick RD, Byers JT, Meguid C, Gajdos C, McCarter MD. Neoadjuvant FOLFIRINOX application in borderline resectable pancreatic adenocarcinoma: a retrospective cohort study. Medicine (Baltimore). 2014;93:e198

70. Rose JB, Rocha FG, Alseidi A, Biehl T, Moonka R, Ryan JA, Lin B, Picozzi V, Helton S. Extended neoadjuvant chemotherapy for borderline resectable 
pancreatic cancer demonstrates promising postoperative outcomes and survival. Ann Surg Oncol. 2014;21:1530-7.

71. Sahora K, Schindl M, Kuehrer I, Eisenhut A, Werba G, Brostjan C, Telek B, Ba'ssalamah A, Stift J, Schoppmann SF, Gnant M. A phase II trial of two durations of Bevacizumab added to neoadjuvant gemcitabine for borderline and locally advanced pancreatic cancer. Anticancer Res. 2014;34:2377-84.

72. Takeda Y, Nakamori S, Eguchi H, Kobayashi S, Marubashi S, Tanemura M, Konishi K, Yoshioka Y, Umeshita K, Mori M, et al. Neoadjuvant gemcitabine-based accelerated hyperfractionation chemoradiotherapy for patients with borderline resectable pancreatic adenocarcinoma. Jpn J Clin Oncol. 2014;44:1172-80.

73. Tzeng CW, Balachandran A, Ahmad M, Lee JE, Krishnan S, Wang H, Crane CH, Wolff RA, Varadhachary GR, Pisters PW, et al. Serum carbohydrate antigen 19-9 represents a marker of response to neoadjuvant therapy in patients with borderline resectable pancreatic cancer. HPB (Oxford). 2014;16:430-8.

74. Tzeng CW, Tran Cao HS, Lee JE, Pisters PW, Varadhachary GR, Wolff RA Abbruzzese JL, Crane CH, Evans DB, Wang H, et al. Treatment sequencing for resectable pancreatic cancer: influence of early metastases and surgical complications on multimodality therapy completion and survival. J Gastrointest Surg. 2014;18:16-24. discussion 24-15

75. Wo JY, Mamon HJ, Ferrone CR, Ryan DP, Blaszkowsky LS, Kwak EL, Tseng YD, Napolitano BN, Ancukiewicz M, Swanson RS, et al. Phase I study of neoadjuvant accelerated short course radiation therapy with photons and capecitabine for resectable pancreatic cancer. Radiother Oncol. 2014;110:160-4.

76. Alvarez R, Musteanu M, Garcia-Garcia E, Lopez-Casas PP, Megias D, Guerra C, Munoz M, Quijano Y, Cubillo A, Rodriguez-Pascual J, et al. Stromal disrupting effects of nab-paclitaxel in pancreatic cancer. Br J Cancer. 2013;109:926-33.

77. Araujo RL, Gaujoux S, Huguet F, Gonen M, D'Angelica MI, DeMatteo RP, Fong Y, Kingham TP, Jarnagin WR, Goodman KA, Allen PJ. Does preoperative chemoradiation for initially unresectable or borderline resectable pancreatic adenocarcinoma increase post-operative morbidity? A casematched analysis. HPB (Oxford). 2013;15:574-80.

78. Boone BA, Steve J, Krasinskas AM, Zureikat AH, Lembersky BC, Gibson MK, Stoller RG, Zeh HJ, Bahary N. Outcomes with FOLFIRINOX for borderline resectable and locally unresectable pancreatic cancer. J Surg Oncol. 2013:108:236-41.

79. Cetin V, Piperdi B, Bathini V, Walsh WV, Yunus S, Tseng JF, Whalen GF, Wassef WY, Kadish SP, Fitzgerald TJ, et al. A phase II trial of Cetuximab, Gemcitabine, 5-fluorouracil, and radiation therapy in locally advanced nonmetastatic pancreatic Adenocarcinoma. Gastrointest Cancer Res. 2013;6:S2-9.

80. Cho IR, Chung MJ, Bang S, Park SW, Chung JB, Song SY, Seong J, Hwang HK, Kang CM, Lee WJ, Park JY. Gemcitabine based neoadjuvant chemoradiotherapy therapy in patients with borderline resectable pancreatic cancer. Pancreatology. 2013;13:539-43.

81. Chuong MD, Springett GM, Freilich JM, Park CK, Weber JM, Mellon EA, Hodul PJ, Malafa MP, Meredith KL, Hoffe SE, Shridhar R. Stereotactic body radiation therapy for locally advanced and borderline resectable pancreatic cancer is effective and well tolerated. Int J Radiat Oncol Biol Phys. 2013;86:516-22.

82. Faris JE, Blaszkowsky LS, McDermott S, Guimaraes AR, Szymonifka J, Huynh MA, Ferrone CR, Wargo JA, Allen JN, Dias LE, et al. FOLFIRINOX in locally advanced pancreatic cancer: the Massachusetts General Hospital cancer center experience. Oncologist. 2013;18:543-8.

83. Gunturu KS, Yao X, Cong X, Thumar JR, Hochster HS, Stein SM, Lacy J. FOLFIRINOX for locally advanced and metastatic pancreatic cancer: single institution retrospective review of efficacy and toxicity. Med Oncol. 2013;30:361.

84. Gurka MK, Collins SP, Slack R, Tse G, Charabaty A, Ley L, Berzcel L, Lei S, Suy $\mathrm{S}$, Haddad N, et al. Stereotactic body radiation therapy with concurrent fulldose gemcitabine for locally advanced pancreatic cancer: a pilot trial demonstrating safety. Radiat Oncol. 2013;8:44.

85. Kim EJ, Ben-Josef E, Herman JM, Bekaii-Saab T, Dawson LA, Griffith KA, Francis IR, Greenson JK, Simeone DM, Lawrence TS, et al. A multi-institutional phase 2 study of neoadjuvant gemcitabine and oxaliplatin with radiation therapy in patients with pancreatic cancer. Cancer. 2013;119:2692-700

86. Leone F, Gatti M, Massucco P, Colombi F, Sperti E, Campanella D, Regge D, Gabriele P, Capussotti L, Aglietta M. Induction gemcitabine and oxaliplatin therapy followed by a twice-weekly infusion of gemcitabine and concurrent external-beam radiation for neoadjuvant treatment of locally advanced pancreatic cancer: a single institutional experience. Cancer. 2013;119:277-84.

87. Mahaseth H, Brutcher E, Kauh J, Hawk N, Kim S, Chen Z, Kooby DA, Maithel SK, Landry J, El-Rayes BF. Modified FOLFIRINOX regimen with improved safety and maintained efficacy in pancreatic adenocarcinoma. Pancreas. 2013:42:1311-5.
88. Rajagopalan MS, Heron DE, Wegner RE, Zeh HJ, Bahary N, Krasinskas AM, Lembersky B, Brand R, Moser AJ, Quinn AE, Burton SA. Pathologic response with neoadjuvant chemotherapy and stereotactic body radiotherapy for borderline resectable and locally-advanced pancreatic cancer. Radiat Oncol. 2013;8:254.

89. Shinoto M, Yamada S, Yasuda S, Imada H, Shioyama Y, Honda H, Kamada T, Tsujii H, Saisho H. Phase 1 trial of preoperative, short-course carbon-ion radiotherapy for patients with resectable pancreatic cancer. Cancer. 2013;119:45-51.

90. Sho M, Akahori T, Tanaka T, Kinoshita S, Tamamoto T, Nomi T, Yamato I, Hokuto D, Yasuda S, Kawaguchi C, et al. Pathological and clinical impact of neoadjuvant chemoradiotherapy using full-dose gemcitabine and concurrent radiation for resectable pancreatic cancer. J Hepatobiliary Pancreat Sci. 2013;20:197-205.

91. Tajima H, Kitagawa H, Tsukada T, Nakanuma S, Okamoto K, Sakai S, Makino I, Furukawa H, Nakamura K, Hayashi H, et al. A phase I study of neoadjuvant chemotherapy with gemcitabine plus oral S-1 for resectable pancreatic cancer. Mol Clin Oncol. 2013;1:768-72.

92. Tinchon C, Hubmann E, Pichler A, Keil F, Pichler M, Rabl H, Uggowitzer M, Jilek K, Leitner G, Bauernhofer T. Safety and efficacy of neoadjuvant FOLFIRINOX treatment in a series of patients with borderline resectable pancreatic ductal adenocarcinoma. Acta Oncol. 2013;52:1231-3.

93. Arvold ND, Ryan DP, Niemierko A, Blaszkowsky LS, Kwak EL, Wo JY, Allen JN, Clark JW, Wadlow RC, Zhu AX, et al. Long-term outcomes of neoadjuvant chemotherapy before chemoradiation for locally advanced pancreatic cancer. Cancer. 2012;118:3026-35.

94. Barugola G, Partelli S, Crippa S, Capelli P, D'Onofrio M, Pederzoli P, Falconi M. Outcomes after resection of locally advanced or borderline resectable pancreatic cancer after neoadjuvant therapy. Am J Surg. 2012;203:132-9.

95. Bickenbach KA, Gonen M, Tang LH, O'Reilly E, Goodman K, Brennan MF, D'Angelica MI, Dematteo RP, Fong Y, Jarnagin WR, Allen PJ. Downstaging in pancreatic cancer: a matched analysis of patients resected following systemic treatment of initially locally unresectable disease. Ann Surg Oncol. 2012;19:1663-9.

96. Habermehl D, Kessel K, Welzel T, Hof H, Abdollahi A, Bergmann F, Rieken S, Weitz J, Werner J, Schirmacher P, et al. Neoadjuvant chemoradiation with Gemcitabine for locally advanced pancreatic cancer. Radiat Oncol. 2012;7:28.

97. Hosein PJ, Macintyre J, Kawamura C, Maldonado JC, Ernani V, Loaiza-Bonilla A, Narayanan G, Ribeiro A, Portelance L, Merchan JR, et al. A retrospective study of neoadjuvant FOLFIRINOX in unresectable or borderline-resectable locally advanced pancreatic adenocarcinoma. BMC Cancer. 2012;12:199.

98. De Jesus-Acosta A, Oliver GR, Blackford A, Kinsman K, Flores El, Wilfong LS, Zheng L, Donehower RC, Cosgrove D, Laheru D, et al. A multicenter analysis of GTX chemotherapy in patients with locally advanced and metastatic pancreatic adenocarcinoma. Cancer Chemother Pharmacol. 2012;69:415-24.

99. Kang CM, Chung YE, Park JY, Sung JS, Hwang HK, Choi HJ, Kim H, Song SY, Lee WJ. Potential contribution of preoperative neoadjuvant concurrent chemoradiation therapy on margin-negative resection in borderline resectable pancreatic cancer. J Gastrointest Surg. 2012;16:509-17.

100. Lee JL, Kim SC, Kim JH, Lee SS, Kim TW. Park do H, Seo DW, lee SK, Kim MH, $\mathrm{Kim} J \mathrm{H}$, et al: prospective efficacy and safety study of neoadjuvant gemcitabine with capecitabine combination chemotherapy for borderlineresectable or unresectable locally advanced pancreatic adenocarcinoma. Surgery. 2012;152:851-62.

101. Papalezova KT, Tyler DS, Blazer DG, Clary BM, Czito BG, Hurwitz HI, Uronis HE, Pappas TN, Willett CG, White RR. Does preoperative therapy optimize outcomes in patients with resectable pancreatic cancer? J Surg Oncol. 2012;106:111-8.

102. Peddi PF, Lubner S, McWilliams R, Tan BR, Picus J, Sorscher SM, Suresh R, Lockhart AC, Wang J, Menias C, et al. Multi-institutional experience with FOLFIRINOX in pancreatic adenocarcinoma. JOP. 2012;13:497-501.

103. Tajima H, Ohta T, Kitagawa H, Okamoto K, Sakai S, Makino I, Kinoshita J, Furukawa $\mathrm{H}$, Nakamura K, Hayashi $\mathrm{H}$, et al. Pilot study of neoadjuvant chemotherapy with gemcitabine and oral S-1 for resectable pancreatic cancer. Exp Ther Med. 2012;3:787-92.

104. Takahashi H, Ohigashi H, Ishikawa O, Gotoh K, Yamada T, Nagata S, Tomita $Y$, Eguchi $H$, Doki Y, Yano M. Perineural invasion and lymph node involvement as indicators of surgical outcome and pattern of recurrence in the setting of preoperative gemcitabine-based chemoradiation therapy for resectable pancreatic cancer. Ann Surg. 2012;255:95-102.

105. Loehrer PJ Sr, Feng Y, Cardenes H, Wagner L, Brell JM, Cella D, Flynn P, Ramanathan RK, Crane CH, Alberts SR, Benson AB 3rd. Gemcitabine alone 
versus gemcitabine plus radiotherapy in patients with locally advanced pancreatic cancer: an eastern cooperative oncology group trial. J Clin Oncol. 2011;29:4105-12.

106. Milandri C, Polico R, Garcea D, Passardi A, Gardini A, Romeo A, Scarpi E, Rosetti P, Ridolfi L, La Barba G, et al. GEMOX plus tomotherapy for unresectable locally advanced pancreatic cancer. Hepato-Gastroenterology. 2011;58:599-603.

107. Patel M, Hoffe S, Malafa M, Hodul P, Klapman J, Centeno B, Kim J, Helm J, Valone T, Springett G. Neoadjuvant GTX chemotherapy and IMRT-based chemoradiation for borderline resectable pancreatic cancer. J Surg Oncol. 2011;104:155-61.

108. Sahora K, Kuehrer I, Eisenhut A, Akan B, Koellblinger C, Goetzinger P, Teleky B, Jakesz R, Peck-Radosavljevic M, Ba'ssalamah A, et al. NeoGemOx: Gemcitabine and oxaliplatin as neoadjuvant treatment for locally advanced, nonmetastasized pancreatic cancer. Surgery. 2011:149:311-20.

109. Sahora K, Kuehrer I, Schindl M, Koelblinger C, Goetzinger P, Gnant M. NeoGemTax: gemcitabine and docetaxel as neoadjuvant treatment for locally advanced nonmetastasized pancreatic cancer. World J Surg. 2011;35:1580-9.

110. Schellenberg D, Kim J, Christman-Skieller C, Chun CL, Columbo LA, Ford JM, Fisher GA, Kunz PL, Van Dam J, Quon A, et al. Single-fraction stereotactic body radiation therapy and sequential gemcitabine for the treatment of locally advanced pancreatic cancer. Int J Radiat Oncol Biol Phys. 2011;81:181-8.

111. Small W Jr, Mulcahy MF, Rademaker A, Bentrem DJ, Benson AB, Weitner BB, Talamonti MS. Phase II trial of full-dose gemcitabine and bevacizumab in combination with attenuated three-dimensional conformal radiotherapy in patients with localized pancreatic cancer. Int J Radiat Oncol Biol Phys. 2011:80:476-82

112. Stokes JB, Nolan NJ, Stelow EB, Walters DM, Weiss GR, de Lange EE, Rich TA, Adams RB, Bauer TW. Preoperative capecitabine and concurrent radiation for borderline resectable pancreatic cancer. Ann Surg Oncol. 2011;18:619-27.

113. Katz MH, Varadhachary GR, Fleming JB, Wolff RA, Lee JE, Pisters PW, Vauthey JN, Abdalla EK, Sun CC, Wang H, et al. Serum CA 19-9 as a marker of resectability and survival in patients with potentially resectable pancreatic cancer treated with neoadjuvant chemoradiation. Ann Surg Oncol. 2010;17:1794-801.

114. Landry J, Catalano PJ, Staley C, Harris W, Hoffman J, Talamonti M, Xu N, Cooper $\mathrm{H}$, Benson AB 3rd. Randomized phase II study of gemcitabine plus radiotherapy versus gemcitabine, 5-fluorouracil, and cisplatin followed by radiotherapy and 5-fluorouracil for patients with locally advanced, potentially resectable pancreatic adenocarcinoma. J Surg Oncol. 2010;101:587-92.

115. Mahadevan A, Jain S, Goldstein M, Miksad R, Pleskow D, Sawhney M, Brennan D, Callery M, Vollmer C. Stereotactic body radiotherapy and gemcitabine for locally advanced pancreatic cancer. Int J Radiat Oncol Biol Phys. 2010;78:735-42.

116. Mattiucci GC, Morganti AG, Valentini V, Ippolito E, Alfieri S, Antinori A, Crucitti A, D'Agostino GR, Di Lullo L, Luzi S, et al. External beam radiotherapy plus 24 -hour continuous infusion of gemcitabine in unresectable pancreatic carcinoma: long-term results of a phase II study. Int J Radiat Oncol Biol Phys. 2010;76:831-8.

117. McClaine RJ, Lowy AM, Sussman JJ, Schmulewitz N, Grisell DL, Ahmad SA. Neoadjuvant therapy may lead to successful surgical resection and improved survival in patients with borderline resectable pancreatic cancer. HPB (Oxford). 2010;12:73-9.

118. Polistina F, Costantin G, Casamassima F, Francescon P, Guglielmi R, Panizzoni G, Febbraro A, Ambrosino G. Unresectable locally advanced pancreatic cancer: a multimodal treatment using neoadjuvant chemoradiotherapy (gemcitabine plus stereotactic radiosurgery) and subsequent surgical exploration. Ann Surg Oncol. 2010;17:2092-101.

119. Turrini O, Ychou M, Moureau-Zabotto L, Rouanet P, Giovannini M, Moutardier V, Azria D, Delpero JR, Viret F. Neoadjuvant docetaxel-based chemoradiation for resectable adenocarcinoma of the pancreas: new neoadjuvant regimen was safe and provided an interesting pathologic response. Eur J Surg Oncol. 2010;36:987-92.

120. Bjerregaard JK, Mortensen MB, Jensen HA, Fristrup C, Svolgaard B, Schonnemann KR, Hansen TP, Nielsen M, Johansen J, Pfeiffer P. Long-term results of concurrent radiotherapy and UFT in patients with locally advanced pancreatic cancer. Radiother Oncol. 2009:92:226-30.

121. Le Scodan R, Mornex F, Girard N, Mercier C, Valette PJ, Ychou M, Bibeau F, Roy P, Scoazec JY, Partensky C. Preoperative chemoradiation in potentially resectable pancreatic adenocarcinoma: feasibility, treatment effect evaluation and prognostic factors, analysis of the SFRO-FFCD 9704 trial and literature review. Ann Oncol. 2009;20:1387-96.
122. Maximous DW, Abdel-Wanis ME, El-Sayed MI, Abd-Elsayed AA. Preoperative gemcitabine based chemo-radiotherapy in locally advanced non metastatic pancreatic adenocarcinoma. Int Arch Med. 2009;2:7.

123. Satoi $S$, Yanagimoto $H$, Toyokawa $H$, Takahashi K, Matsui $Y$, Kitade $H$, Mergental H, Tanigawa N, Takai S, Kwon AH. Surgical results after preoperative chemoradiation therapy for patients with pancreatic cancer. Pancreas. 2009;38:282-8.

124. Tinkl D, Grabenbauer GG, Golcher H, Meyer T, Papadopoulos T, Hohenberger W, Sauer R, Brunner TB. Downstaging of pancreatic carcinoma after neoadjuvant chemoradiation. Strahlenther Onkol. 2009;185:557-66.

125. Wilkowski R, Boeck S, Ostermaier S, Sauer R, Herbst M, Fietkau R, Flentje M, Miethe S, Boettcher HD, Scholten T, et al. Chemoradiotherapy with concurrent gemcitabine and cisplatin with or without sequential chemotherapy with gemcitabine/cisplatin vs chemoradiotherapy with concurrent 5-fluorouracil in patients with locally advanced pancreatic cancer-a multi-centre randomised phase II study. Br J Cancer. 2009;101:1853-9.

126. Winter JM, Cameron JL, Campbell KA, Arnold MA, Chang DC, Coleman J, Hodgin MB, Sauter PK, Hruban RH, Riall TS, et al. 1423 Pancreaticoduodenectomies for pancreatic cancer: a single-institution experience. J Gastrointest Surg. 2006;10:1199-210. discussion 1210-1191

127. Fatima J, Schnelldorfer T, Barton J, et al. Pancreatoduodenectomy for ductal adenocarcinoma: implications of positive margin on survival. Arch Surg. 2010;145:167-72.

128. Konstantinidis IT, Warshaw AL, Allen JN, Blaszkowsky LS, Castillo CF, Deshpande V, Hong TS, Kwak EL, Lauwers GY, Ryan DP, et al. Pancreatic ductal adenocarcinoma: is there a survival difference for $\mathrm{R} 1$ resections versus locally advanced unresectable tumors? What is a "true" R0 resection? Ann Surg. 2013;257:731-6.

129. Neoptolemos JP, Stocken DD, Bassi C, et al. Adjuvant chemotherapy with fluorouracil plus folinic acid vs gemcitabine following pancreatic cancer resection: a randomized controlled trial. JAMA. 2010;304:1073-81.

130. Regine WF, Winter KA, Abrams RA, et al. Fluorouracil vs gemcitabine chemotherapy before and after fluorouracil-based chemoradiation following resection of pancreatic adenocarcinoma: a randomized controlled trial. JAMA. 2008;299:1019-26.

131. Evans DB, Varadhachary GR, Crane CH, Sun CC, Lee JE, Pisters PWT, Vauthey J-N, Wang H, Cleary KR, Staerkel GA, et al. Preoperative Gemcitabine-based Chemoradiation for patients with Resectable Adenocarcinoma of the pancreatic head. J Clin Oncol. 2008;26:3496-502.

132. Varadhachary GR, Wolff RA, Crane CH, Sun CC, Lee JE, Pisters PWT, Vauthey J-N, Abdalla E, Wang H, Staerkel GA, et al. Preoperative Gemcitabine and Cisplatin followed by Gemcitabine-based Chemoradiation for Resectable Adenocarcinoma of the pancreatic head. J Clin Oncol. 2008;26:3487-95.

133. Neoptolemos JP, Stocken DD, Friess H, Bassi C, Dunn JA, Hickey H, Beger $H_{\text {, }}$ Fernandez-Cruz L, Dervenis C, Lacaine F, et al. A randomized trial of Chemoradiotherapy and chemotherapy after resection of pancreatic cancer. N Engl J Med. 2004;350:1200-10.

134. Oettle $H$, Neuhaus $P$, Hochhaus A, et al. Adjuvant chemotherapy with gemcitabine and long-term outcomes among patients with resected pancreatic cancer: the conko-001 randomized trial. JAMA. 2013;310:1473-81.

135. Neoptolemos JP, Palmer DH, Ghaneh P, Psarelli EE, Valle JW, Halloran CM, Faluyi O, O'Reilly DA, Cunningham D, Wadsley J, et al. Comparison of adjuvant gemcitabine and capecitabine with gemcitabine monotherapy in patients with resected pancreatic cancer (ESPAC-4): a multicentre, openlabel, randomised, phase 3 trial. Lancet. 389:1011-24.

136. Sohal D, McDonough SL, Ahmad SA, Gandhi N, Beg MS, Wang-Gillam A, Guthrie KA, Lowy AM, Philip PA, Hochster HS. SWOG S1505: a randomized phase II study of perioperative mFOLFIRINOX vs. gemcitabine/nab-paclitaxel as therapy for resectable pancreatic adenocarcinom. J Clin Oncol. 2017;35:-TPS508.

137. Suker M, Beumer BR, Sadot E, Marthey L, Faris JE, Mellon EA, El-Rayes BF, Wang-Gillam A, Lacy J, Hosein PJ, et al. FOLFIRINOX for locally advanced pancreatic cancer: a systematic review and patient-level meta-analysis. Lancet Oncol. 2016;17:801-10.

138. Evans DB, Rich TA, Byrd DR, et al. Preoperative chemoradiation and pancreaticoduodenectomy for adenocarcinoma of the pancreas. Arch Surg. 1992;127:1335-9.

139. Hartman DJ, Krasinskas AM. Assessing treatment effect in pancreatic cancer. Arch Pathol Lab Med. 2012:136:100-9. 